\title{
The Tropical Subseasonal Variability Simulated in the NASA GISS General Circulation Model
}

\author{
DAehyun Kim,* AdAm H. Sobel,,${ }^{,+, \#}$ Anthony D. Del Genio,${ }^{@}$ Yonghua Chen, ${ }^{+,}$ \\ SuZANA J. CAMARGO,* MAO-SUng YAO, ${ }^{@, \&}$ MAXWEll Kelley, ${ }^{* *}$ AND LARISSA NAZARENKO** \\ * Lamont-Doherty Earth Observatory, Columbia University, Palisades, New York \\ ${ }^{+}$Department of Applied Physics and Applied Mathematics, Columbia University, New York, New York \\ \# Department of Earth and Environmental Sciences, Columbia University, New York, New York \\ ${ }^{\circledR}$ NASA Goddard Institute for Space Studies, New York, New York \\ \& Trinnovim, Goddard Institute for Space Studies, New York, New York \\ ** Center for Climate Systems Research, Columbia University, New York, New York
}

(Manuscript received 12 August 2011, in final form 16 December 2011)

\begin{abstract}
The tropical subseasonal variability simulated by the Goddard Institute for Space Studies general circulation model, Model E2, is examined. Several versions of Model E2 were developed with changes to the convective parameterization in order to improve the simulation of the Madden-Julian oscillation (MJO). When the convective scheme is modified to have a greater fractional entrainment rate, Model E2 is able to simulate MJO-like disturbances with proper spatial and temporal scales. Increasing the rate of rain reevaporation has additional positive impacts on the simulated MJO. The improvement in MJO simulation comes at the cost of increased biases in the mean state, consistent in structure and amplitude with those found in other GCMs when tuned to have a stronger MJO. By reinitializing a relatively poor-MJO version with restart files from a relatively better-MJO version, a series of 30-day integrations is constructed to examine the impacts of the parameterization changes on the organization of tropical convection. The poor-MJO version with smaller entrainment rate has a tendency to allow convection to be activated over a broader area and to reduce the contrast between dry and wet regimes so that tropical convection becomes less organized. Besides the MJO, the number of tropical-cyclone-like vortices simulated by the model is also affected by changes in the convection scheme. The model simulates a smaller number of such storms globally with a larger entrainment rate, while the number increases significantly with a greater rain reevaporation rate.
\end{abstract}

\section{Introduction}

In the tropics, there are a number of distinct modes of variability with time scales shorter than a season. On synoptic time scales (say, 2-10 days), these include convectively coupled waves (e.g., Wheeler and Kiladis 1999) and tropical cyclones (TCs). On a somewhat longer time scale, the Madden-Julian oscillation (MJO) (Madden and Julian 1971, 1972) is the dominant mode of tropical intraseasonal variability (ISV), characterized by its planetary spatial scale, 30-60-day period and eastward propagation. As it modulates deep convection over the tropics, the MJO has large impacts on a wide variety of climate phenomena across different spatial and temporal

Corresponding author address: Daehyun Kim, Lamont-Doherty Earth Observatory, 61 Rte. 9W, Palisades, NY 10964-1000.

E-mail: dkim@ldeo.columbia.edu scales. Some examples include the onsets and breaks of the Indian and Australian summer monsoons (e.g., Yasunari 1979; Wheeler and McBride 2005), the formation of TCs (e.g., Liebmann et al. 1994; Maloney and Hartmann 2000b,a; Bessafi and Wheeler 2006; Camargo et al. 2009), and the onset of some El Niño events (e.g., Takayabu et al. 1999; Bergman et al. 2001; Kessler 2001).

Previous studies have demonstrated that the simulation of the MJO can be improved by changing specific aspects of the cumulus parameterization of the GCM. The changes that have been made to this end differ in detail but have in common the tendency to inhibit deep cumulus convection (Tokioka et al. 1988; Wang and Schlesinger 1999; Maloney and Hartmann 2001; Lee et al. 2003; Zhang and Mu 2005; Lin et al. 2008). Simulation of the MJO, however, has been a difficult test for most climate models, from the Atmospheric Model Intercomparison Project (AMIP) (Slingo et al. 1996) to the 
more recent Coupled Model Intercomparison Project phase 3 (CMIP3) (Lin et al. 2006) used in the Fourth Assessment Report (AR4) of the United Nations Intergovernmental Panel on Climate Change. Lin et al. (2006) showed that only 2 among 14 models in AR4 had MJO variance comparable to observations, with even those lacking realism in many other MJO features. Kim et al. (2011b) attributed this common symptom to a systematic relationship between a model's MJO strength and its mean bias. They showed that a specific set of mean state biases worsen as a result of the same parameterization changes that strengthen the MJO mode in a number of different models. This suggests that those parameterization changes may have been rejected because of higher priorities placed on the mean state simulation compared to the MJO simulation.

Lin et al. (2006) showed that the National Aeronautics and Space Administration Goddard Institute for Space Studies (GISS) GCM Model E-R (GISS-ER) in AR4 had no MJO. Here we use the Fifth Assessment Report (AR5) version of the GISS GCM-Model E2-which is different from the AR4 version in many aspects including its parameterization of cumulus convection and clouds (see section 2a). As will be shown later in section 3, the AR5 version is not able to simulate the MJO either. The first question that we address in this study is whether parameterization changes similar to those used in other models to improve the simulation of the MJO are also effective in the GISS model.

The second question is how the changes in the cumulus convection scheme that improve the simulation of the MJO do so. To this end, we present several diagnostics aimed at providing insight into the relevant physical processes. We also use short-term integrations in which instantaneous model states from a simulation with one model version are used as the initial conditions for the simulations with another model version. This approach is similar to that of Boyle et al. (2008) and Willett et al. (2008), who performed short-term integrations of a GCM during a strong-MJO period. They initialized the model every day using reanalysis data and studied the growth of the deviation of the model field from the observed state with the aim of identifying the physical processes responsible for the deviation. We adapt this methodology to identify key differences between those two versions of the same GCM rather than to compare one GCM to observations. For this purpose, we initialize a version of the GCM that simulates the MJO poorly with initial conditions from one that simulates it better.

Tuning a convection scheme to improve the intraseasonal variability-MJO affects longer and shorter time scales of climate as well. We address here how the parameterization changes that improve the MJO simulation simultaneously influence both the mean state and the number of TC-like vortices. The systematic variation of the mean state with the MJO simulation in other GCMs was reported in Kim et al. (2011b). Sensitivity of the TC-like vortex activity to the physical parameterizations in lowresolution GCMs has been reported (Vitart et al. 2001; Yoshimura et al. 2006; LaRow et al. 2008), but to our knowledge there has been no attempt to investigate a linkage between the sensitivity of TC-like vortices to that of the MJO.

In this study, we investigate one particular modelModel E2-to address the above issues. For this purpose, we use several versions of Model E2, differing in details of the convective parameterization. Model E2 and the observational data used are described briefly in section 2 , followed by a description of sensitivity experiments performed in section 3 . One version of the model with a reasonable representation of the MJO is selected and analyzed in detail in section 4. Results from the reinitialization experiments that aim to understand the difference between the selected version and the relatively worse MJO version are presented in section 5 . The sensitivity of the number of TC-like vortices to the same modifications that improve the MJO simulation is analyzed in section 6. Summary and conclusions are given in section 7 .

\section{Model and data}

\section{a. Model E2 GCM}

The atmospheric component of the GISS Model E GCM (Schmidt et al. 2006) was used in the IPCC AR4 with a resolution of $4^{\circ}$ latitude $\times 5^{\circ}$ longitude $\times 20$ levels (L). For the Fifth Assessment Report, simulations are being conducted with the newer Model E2 (Schmidt et al. 2012, manuscript in preparation) at a resolution of $2^{\circ} \times$ $2.5^{\circ} \times 40 \mathrm{~L}$. This serves as the control version of the model in this paper, to which other modified versions will be compared. Model E2 contains numerous changes to the cumulus parameterization relative to Model E. Among the most important are the following. 1) Convective entrainment and updraft speed are diagnosed using the parameterization of Gregory (2001), as described in Del Genio et al. (2007), with different values of the entrainment coefficients to capture less entraining and more entraining components of the mass flux. 2) Convective condensate in small particles whose fall speeds are significantly less than the updraft speed is transported upward rather than immediately detraining as in Del Genio et al. (2005); the portion of frozen condensate in the form of graupel extends up to a minimum temperature that depends on updraft speed. 3) Downdrafts originate from multiple levels above cloud base and detrain at all lower 
levels, including below cloud base; downdrafts entrain/ detrain momentum as well as heat and moisture; downdraft mass fluxes are used to calculate a gustiness correction to surface fluxes. 4) The convective pressure gradient is assumed to reduce convective momentum transport as in Gregory et al. (1997). 5) The adjustment time for convection to adjust the cloud base to neutral buoyancy is set to $1 \mathrm{~h}$, twice the physics time step. Readers are referred to Kim et al. (2011a) for a more detailed description of the cumulus parameterization in Model E2.

Model E2 also includes changes to the stratiform cloud parameterization; among them are the following. 1) The threshold relative humidity for cloud formation is a function of the large-scale vertical velocity above the boundary layer, with a scale-aware correction for layer thickness. Within the boundary layer the threshold relative humidity is based on an assumed Gaussian distribution of saturation deficit, as in Siebesma et al. (2003), and stratiform clouds do not form in subsaturated air below cloud top in the convective portion of the grid box or below the cloud base of a boundary layer convective cloud. 2) The phase in which cloud forms is maintained until the cloud dissipates unless supercooled liquid is glaciated by the Bergeron-Findeisen process; convective snow is no longer permitted to glaciate a supercooled stratiform cloud. 3) The critical supersaturation for homogeneous nucleation of ice is based on Kärcher and Lohmann (2002). 4) The optical thickness of precipitation is accounted for by the radiation. 5) In unfavorable conditions, stratiform cloud erosion by evaporation up to the threshold relative humidity is allowed. 6) Various changes to the values of parameters that affect autoconversion, maximum cloud particle size, and the temperature dependence of liquid versus ice formation have been made.

\section{b. Sensitivity experiments-Modifications to AR5 version}

\section{1) REMOVAl OF A MASS FLUX LIMITER IN THE CONVECTION SCHEME}

As will be shown (in Fig. 3), the AR5 version of Model E2 (AR5a) lacks any representation of the MJO. This is likely related to the fact that deep convection occurs in the model too frequently and is not sufficiently inhibited when tropospheric moisture is low. To make this point, Fig. 1 shows composited daily precipitation based on daily precipitable water. The inset in Fig. 1a, where we zoom in and show only the bins with precipitable water between 20 and $45 \mathrm{~mm}$, highlights the earlier onset of deep convection in AR5a compared to the model with a greater entrainment rate, AR5a_Ent1 (described below). Figure $1 \mathrm{~b}$, which shows the probability density function of daily precipitable water, informs us that these events are not rare cases.
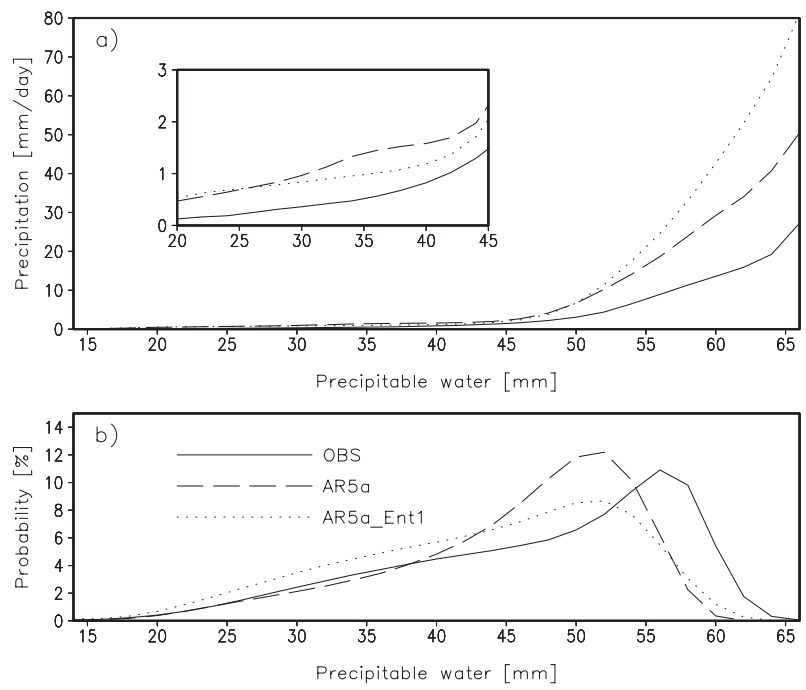

FIG. 1. (a) Precipitation $\left(\mathrm{mm} \mathrm{day}^{-1}\right)$ composited based on precipitable water $(\mathrm{mm})$ and (b) probability of precipitable water from observations (solid), AR5a (dashed), and AR5a_Ent1 (dotted). Only oceanic grid points over the warm pool region $\left(15^{\circ} \mathrm{S}-15^{\circ} \mathrm{N}\right.$, $40^{\circ} \mathrm{E}-180^{\circ}$ ) are used.

Only grid points that have precipitable water between 35 and $45 \mathrm{~mm}$ are used in the composite of the convective heating, based on precipitation in Fig. 2a, to see the mean depth of cumulus clouds simulated in this range of precipitable water. The figure exhibits a deep structure when $\log _{10}$ (precipitation) is greater than 0.5 (precipitation $>3.2 \mathrm{~mm}$ day $^{-1}$ ). This means that deep convection occurs even when precipitable water is between 35 and $45 \mathrm{~mm}, O(50 \%)$ of the saturation value. In observations, cloud top height is strongly modulated by tropospheric moisture (Holloway and Neelin 2009) so that-unlike in the results shown in Fig. 2-deep convection with cloud tops near the tropopause is inhibited unless the column is close to saturation. In the AR5_Ent1 version, which has an increased entrainment rate and simulates a better MJO (Fig. 3) than those in AR5a, the frequency of these deep convection events is reduced (Fig. 2b). Also, the composited precipitation is weaker than that in AR5a when precipitable water is less than about $50 \mathrm{~mm}$, while it is much stronger when precipitable water is greater than $50 \mathrm{~mm}$ (Fig. 1b).

The lower sensitivity of the simulated convection to tropospheric moisture in AR5a is partly caused by an entrainment limiter in the convection scheme. In AR5a the limiter sets the entrainment rate to zero whenever the mass transport by the convective cloud exceeds the mass of the cloud base layer. Once it becomes zero, it becomes an undiluted plume and keeps the zero entrainment rate until cloud top. The undiluted plume can easily reach the tropopause without losing its buoyancy. 


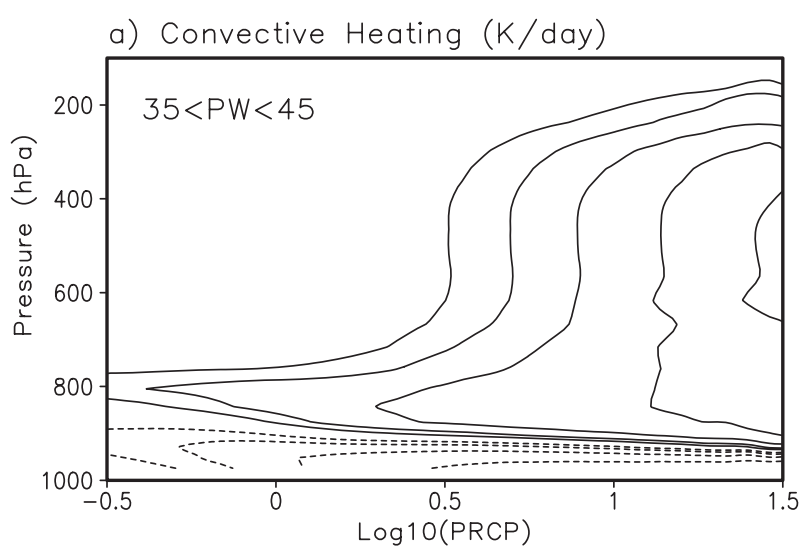

b) Probability (\%)

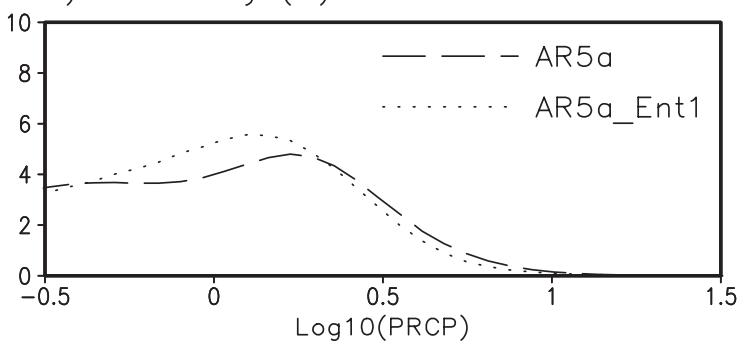

FIG. 2. (a) Convective heating $\left(\mathrm{K} \mathrm{day}^{-1}\right)$ composited based on precipitation from AR5a and (b) probability of precipitation from AR5a (dashed) and AR5a_Ent1 (dotted). Only oceanic grid points over the warm pool region $\left(15^{\circ} \mathrm{S}-15^{\circ} \mathrm{N}, 40^{\circ} \mathrm{E}-180^{\circ}\right)$ with precipitable water between 35 and $45 \mathrm{~mm}$ are used.

Our estimation of the frequency of the "zero entrainment rate" event shows that it happens in about $10 \%$ of convective plumes. This relatively frequent activation of tropopause-deep convection appears to inhibit the largescale organization of convection in the tropics, such as the MJO. In all sensitivity experiments described below, the entrainment limiter described above is modified so that it is activated only when the mass transported in a single time step exceeds the mass of the layer through which the cloud is passing, rather than the cloud base layer. The zero entrainment rate event never happens with this modification.

\section{2) Additional modificAtions to the CONVECTION SCHEME}

A number of sensitivity experiments have been conducted in an attempt to optimize the model simulation of the MJO, convectively coupled waves, and the mean climate. Both entrainment rate coefficients (which control the overall magnitude of the entrainment rate) and the rain reevaporation constant (the fraction of the convective condensate available for rain reevaporation) have been varied in these sensitivity experiments. Specifically, in AR5a_Ent1 a one-plume model with entrainment rate coefficient 0.6 is used instead of the original two-plume structure with entrainment rate coefficients $(0.3,0.6)$. With the modifications in the entrainment limiter, this change effectively increases the entrainment rate in the model, thereby making the plumes in the convection scheme more sensitive to the environmental humidity. Based on AR5_Ent1, more rain reevaporation is allowed in AR5a_Ent1_Re by limiting the maximum amount of condensate used in the downdraft to half of the total condensate. In AR5a, a maximum of all condensate can be used in the downdraft as a source of negative buoyancy. Allowing more rain reevaporation makes it difficult for the convection scheme to produce precipitation in a dry column. Entrainment rates are adjusted to have values between those of AR5a and AR5a_Ent1 in AR5a_Ent2_Re by reviving the two-plume model but with a slightly larger entrainment rate for the less entraining part of the mass flux $(0.4,0.6)$. AR5a_Ent2_Re also allows water vapor and condensate to affect downdraft buoyancy, to offset the suppression of downdrafts caused by increased rain evaporation, and has been adjusted to global radiative balance by tuning the threshold relative humidity value for cloud formation.

Table 1 summarizes the versions of Model E2 used in this study. A series of AMIP-type simulations is performed with these models by prescribing Hadley Centre sea surface temperature data (Rayner et al. 2003) as a boundary condition for the period 1989-2008. The series of 20-yr simulations is conducted at the resolution of $2^{\circ} \times 2.5^{\circ} \times$ 40L except for C_AR5a in which $1^{\circ} \times 1^{\circ} \times 40 \mathrm{~L}$ resolution is used.

\section{c. Observational data}

We validate the simulations of rainfall against the Global Precipitation Climatology Project (GPCP) dataset (Huffman et al. 2001). We use outgoing longwave radiation (OLR) from the Advanced Very High Resolution Radiometer (AVHRR) (Liebmann and Smith 1996). The upper (200 hPa) and lower $(850 \mathrm{hPa})$ tropospheric zonal winds are taken from the National Centers for Environmental Prediction (NCEP)-National Center for Atmospheric Research (NCAR) reanalysis (Kalnay et al. 1996). For the surface latent heat flux we also use the objectively analyzed air-sea fluxes (OAFlux) from $\mathrm{Yu}$ and Weller (2007). The specific humidity and $925-\mathrm{hPa}$ moisture convergence based on the European Centre for Medium-Range Weather Forecasts Interim Re-Analysis (ERA-Interim) (Dee et al. 2011) are also included in our analysis since Tian et al. (2006) indicated possible shortcomings in the MJO-relevant specific humidity fields from the NCEP-NCAR reanalysis. The Special Sensor Microwave Imager (SSM/I)-Tropical Rainfall Measuring Mission (TRMM) Microwave Imager (TMI) combined precipitable water data is also used. The observed TC 
a) $\mathrm{GPCP}$

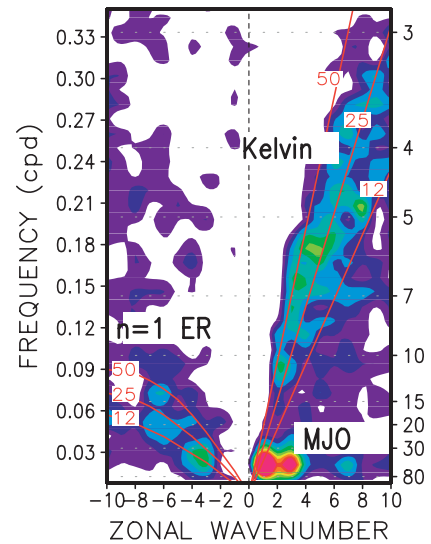

e) $\operatorname{AR} 5 \mathrm{c}$

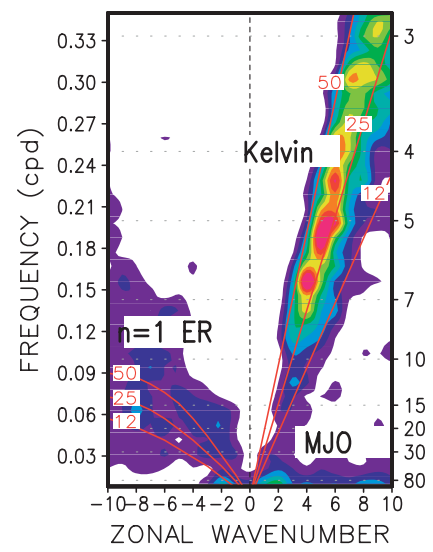

b) $\mathrm{AR} 4 \mathrm{a}$

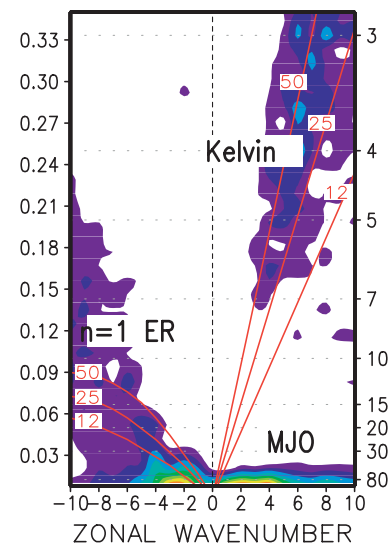

f) AR5a_Ent1

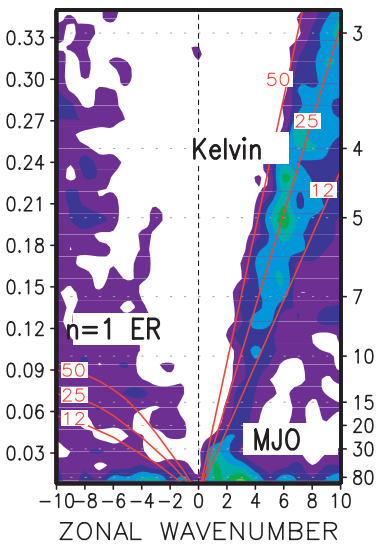

c) AR5a

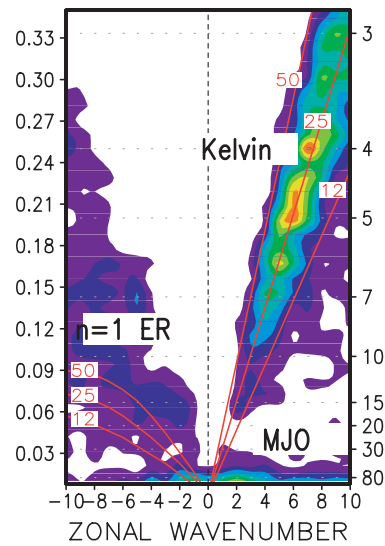

g) AR5a_Ent1_Re

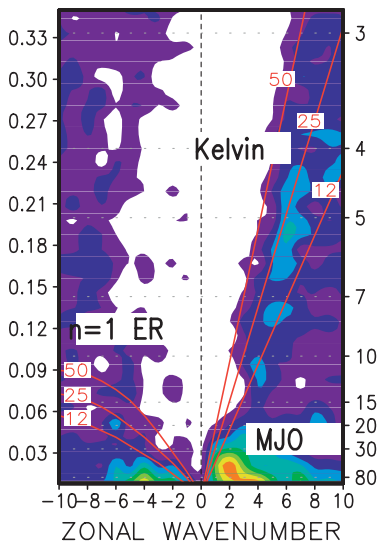

d) C_AR5a

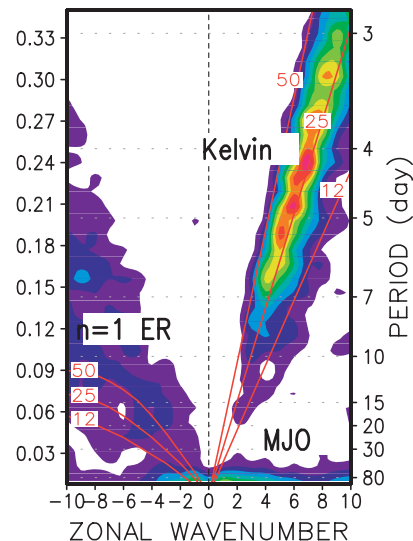

h) AR5a_Ent2_Re

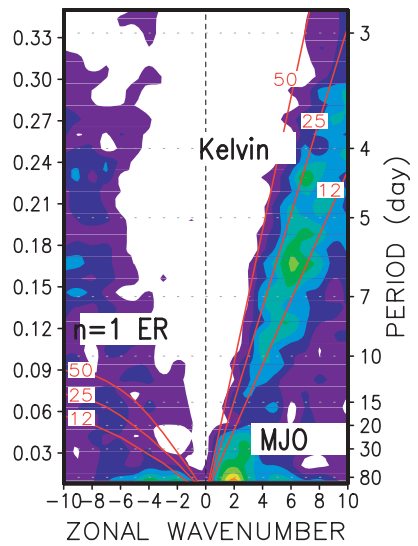

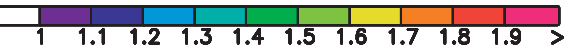

FIG. 3. Space-time spectrum of the $15^{\circ} \mathrm{N}-15^{\circ} \mathrm{S}$ symmetric component of precipitation divided by the background spectrum for (a) GPCP, (b) AR4a, (c) AR5a, (d) C_AR5a, (e) AR5c, (f) AR5a_Ent1, (g) AR5a_Ent1_Re, and (h) AR5a_Ent2_Re. Superimposed are the dispersion curves of the odd-numbered meridional mode equatorial waves for the equivalent depths of 12,25 , and $50 \mathrm{~m}$.

data are from the International Best Track Archive for Climate Stewardship (IBTrACS) dataset (Knapp et al. 2010).

\section{Simulations of the MJO using Model E2}

\section{a. Simulations of the MJO in AR4 and AR5 versions of Model E2}

Following Wheeler and Kiladis (1999), wavenumberfrequency diagrams are constructed to determine the capability of the models to simulate convectively coupled equatorial waves and the MJO. Figure 3 shows the symmetric wavenumber-frequency power spectra [normalized by estimated background power, Wheeler and Kiladis (1999)] of equatorial precipitation from observations and several versions of Model E2. Our focus is on the signals distinct from the background spectrum in the Kelvin, equatorial Rossby wave, and MJO bands (the last being defined as wavenumbers $1-3$, periods 30 60 days) that can be found in the observations (Fig. 3a). The most significant improvement that AR5a has compared to AR4a is its simulation of the Kelvin mode. The Kelvin mode in AR5a is similar to that in observations in both its amplitude and phase speed; the implied equivalent depth is about $25 \mathrm{~m}$. Compared to AR5a, AR4a has a much weaker and faster Kelvin mode, which is also mostly confined to high frequencies (i.e., periods less than 7 days). Despite these improvements, AR5a still lacks the MJO mode.

Figure 3 also contains the symmetric components of the wavenumber-frequency spectra of equatorial precipitation from the different versions of Model E2. The C_AR5a (Fig. 3d) represents a version of Model E2 that uses higher horizontal resolution than that in AR5a by 
TABLE 1. Description of versions of Model E2 used in this study.

\begin{tabular}{ll}
\hline \hline \multicolumn{1}{c}{ Version } & \multicolumn{1}{c}{ Description } \\
\hline AR4a & Atmospheric component of the AR4 version \\
AR5c & Ocean-atmosphere coupled model used in AR5 \\
C_AR5a & Cubed-sphere model used in AR5 \\
AR5a & Atmospheric component of the AR5 version \\
AR5a_Ent1 & One plume with entrainment rate coefficient \\
& 0.6 (based on AR5a) \\
AR5a_Ent1_Re & $\begin{array}{l}\text { Same as above, except for allowing more } \\
\text { rain reevaporation }\end{array}$ \\
AR5a_Ent2_Re & Two plumes with entrainment rate coefficient \\
& (0.4,0.6), allowing more rain reevaporation \\
& (based on AR5a)
\end{tabular}

using the cubed-sphere dynamical core, which replaces the longitude-latitude grid configuration in AR5a. In AR5c (Fig. 3e), we coupled AR5a with an oceanic GCM. At least according to this diagnostic, there is no significant change in the representation of the MJO from AR5a to C_AR5a, or to AR5c, suggesting that the horizontal resolution and air-sea coupling are not crucial factors for the representation of the MJO in Model E2.

\section{b. Simulations of the MJO with changes in convection scheme}

Figure 3 shows that, unlike the control model AR5a, models AR5a_Ent1, AR5a_Ent1_Re, and AR5a_Ent2_Re are able to simulate the MJO to some extent. This suggests that, as shown in previous studies, the moist convection scheme is crucial in the simulation of the MJO using GCMs, with the entrainment rate (Lee et al. 2003; Bechtold et al. 2008; Lin et al. 2008) and the rain reevaporation (Maloney and Hartmann 2001; Kim et al. 2011b) being particularly important. Increasing the entrainment rate and allowing more rain reevaporation strengthens the MJO in the model.

Enhancing rain reevaporation also reduces the speed of the simulated Kelvin waves. The convectively coupled Kelvin waves simulated in AR5a_Ent1_Re and AR5a_Ent2_Re have equivalent depths between 12 and $25 \mathrm{~m}$, while in AR5a_Ent1 and observations the equivalent depth is in the range $25 \sim 50 \mathrm{~m}$. The equivalent depth decreases with increasing water vapor amount in the atmosphere. When we increase the amount of rain reevaporation in the convection scheme, precipitable water increases due to greater evaporation of the condensate. For example, November-April mean precipitable water averaged over the warm pool region $\left(20^{\circ} \mathrm{S}-20^{\circ} \mathrm{N}, 40^{\circ} \mathrm{E}-180^{\circ}\right)$ increases from about $40 \mathrm{~mm}$ in AR5a_Ent1 to about $45 \mathrm{~mm}$ in AR5a_Ent1_Re. Note that the amount of precipitable water becomes closer to the observed value (about $46 \mathrm{~mm}$ ) with increased rain reevaporation.

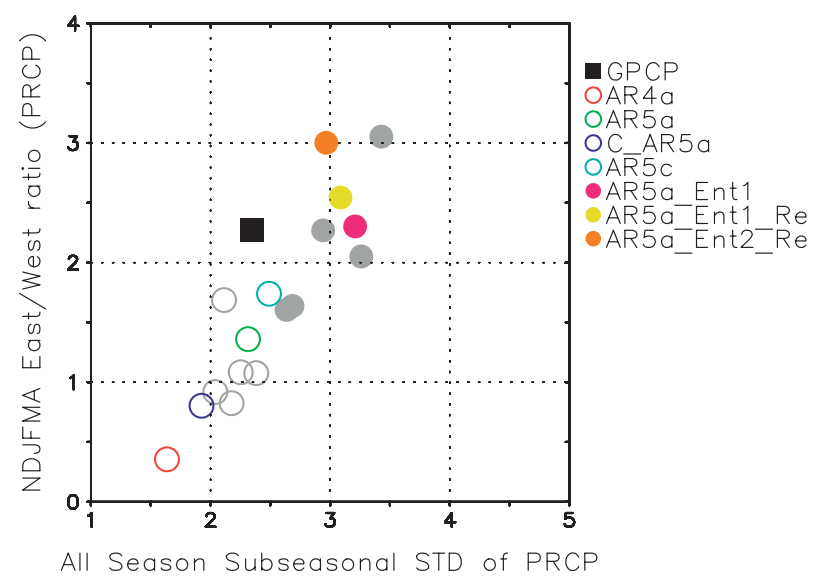

FIG. 4. Scatterplot of November-April standard deviation of 20 100 -day filtered precipitation averaged over $30^{\circ} \mathrm{S}-30^{\circ} \mathrm{N}, 0^{\circ}-360^{\circ}$ and eastward/westward ratio, defined as the ratio of eastwardpropagating spectral power (summation over wavenumbers 1-3, period 30-70 days) to that of the westward propagating counterpart. Open (closed) circles represent the weak (strong) ISV model. Gray circles are the simulations from other GCMs used in Kim et al. (2011b).

To select one model version for more detailed analysis, we looked at other aspects of the simulations in addition to the wavenumber-frequency power spectra. In Fig. 4 the relationship between the strength and the dominant propagation direction of ISV is summarized in a scatter diagram. A similar plot was shown in Kim et al. (2011b) using simulations with other atmospheric models [gray circles in Fig. 4, see Kim et al. (2011b) for further description]. The ISV strength metric is obtained by averaging the standard deviation of 20-100-day filtered precipitation over the tropics $\left(30^{\circ} \mathrm{S}-30^{\circ} \mathrm{N}, 0^{\circ}-360^{\circ}\right)$. For the propagation direction metric, the eastward/westward ratio of ISV is calculated from space-time power spectra by dividing the sum of the spectral power over eastward-propagating zonal wavenumbers 1-3 and frequency range $30-70$ days by its westward propagating counterpart. Figure 4 shows that there is an approximately linear relationship between the two metrics, which is consistent with the Kim et al. results. Overall, versions with ISV strength equal to or less than the observed value of $2.5 \mathrm{~mm}^{2}$ day $^{-2}$ (open circles) underestimate the eastward/westward ratio metric. Strong-ISV versions (ISV > $2.5 \mathrm{~mm}^{2}$ day $^{-2}$, closed circles) generally show eastward/ westward ratios comparable to that of observations and larger than those of the weak-ISV versions.

Kim et al. (2011b) also showed that the strength of the ISV varies systematically with certain aspects of the mean state in the AGCM simulations. To investigate the relationship between ISV characteristics and the mean state in Model E2, May-October mean precipitation is shown in Fig. 5. Although we analyze boreal 
a) GPCP

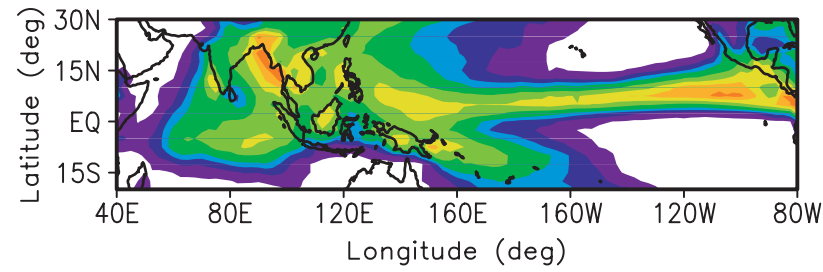

b) $\mathrm{AR} 4 \mathrm{a}$

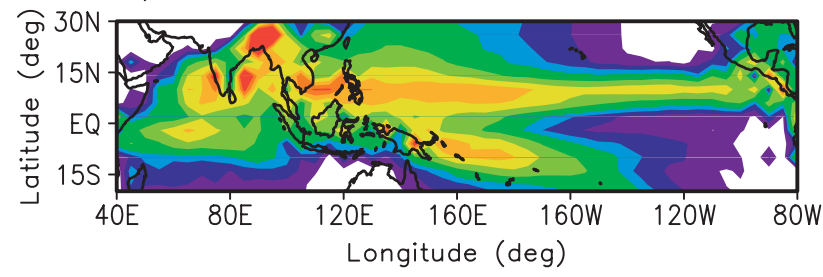

c) $\mathrm{AR} 5 \mathrm{a}$

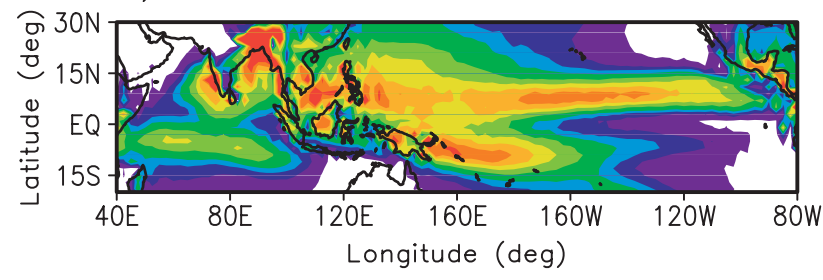

d) C_AR5a

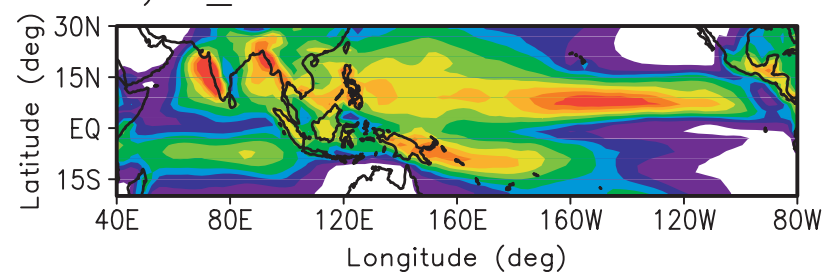

e) $A R 5 c$

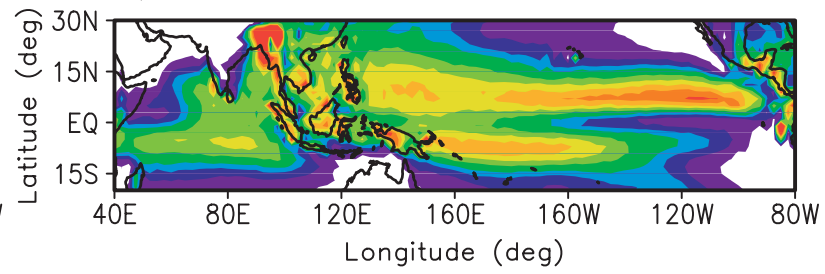

f) AR5a_Ent1

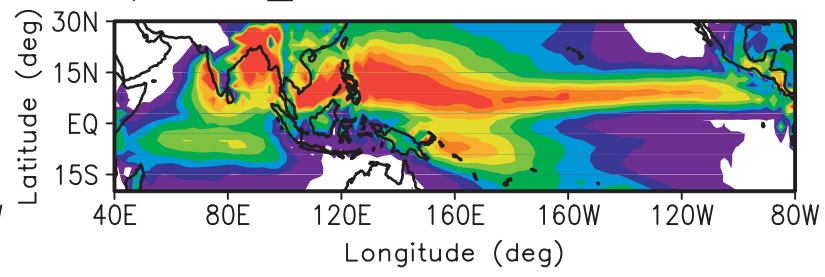

g) AR5a_Ent1_Re

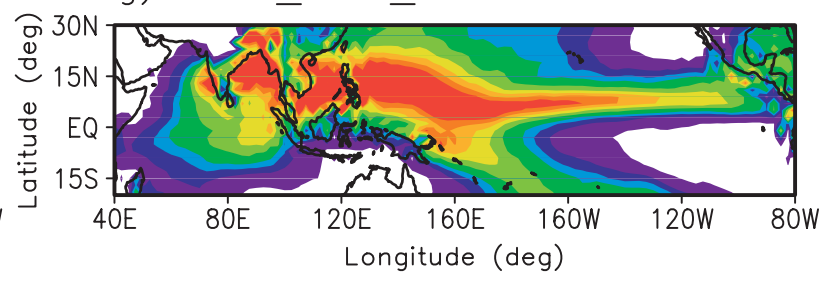

h) AR5a_Ent2_Re

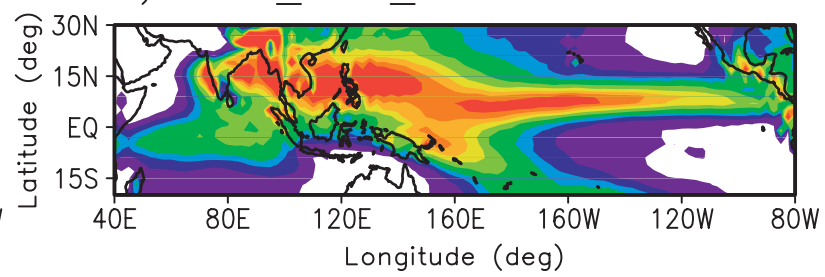

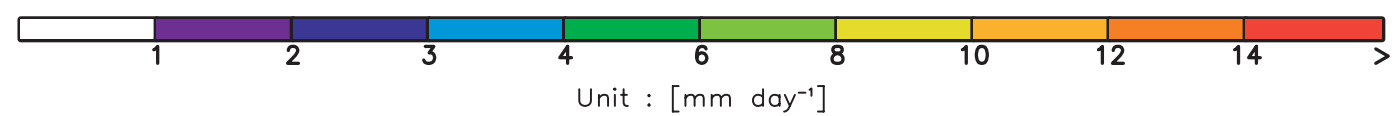

FIG. 5. May-October mean precipitation $\left(\mathrm{mm} \mathrm{day}^{-1}\right.$ ): (a) GPCP, (b) AR4a, (c) AR5a, (d) C_AR5a, (e) AR5c, (f) AR5a_Ent1, (g) AR5a_Ent1_Re, and (h) AR5a_Ent2_Re.

winter data for the following MJO analysis, boreal summer is chosen here because the systematic change in the mean state is greatest in this season, although a qualitatively similar systematic change is also found in boreal winter (Kim et al. 2011b). In Fig. 5, the versions of Model E2 with stronger ISV (closed circles in Fig. 4) tend to simulate excessive mean precipitation over the South China Sea and western Pacific. This is similar to what was documented in Kim et al. (2011b; Fig. 4) using a multimodel dataset.
The aforementioned results suggest that the improvements in the simulation of the MJO obtained by increasing entrainment rates and allowing more rain reevaporation in the convection scheme are accompanied by a larger-than-observed ISV magnitude and a systematic mean state bias consistent with that found in other models. A similar trade-off between biases of different aspects of climate is also discussed in Mapes and Neale (2011). They call it the "entrainment dilemma" and partly overcome the dilemma by implementing 
a) OBS

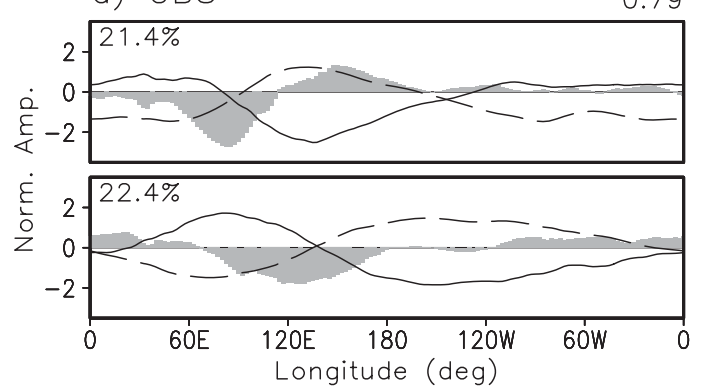

c) OBS

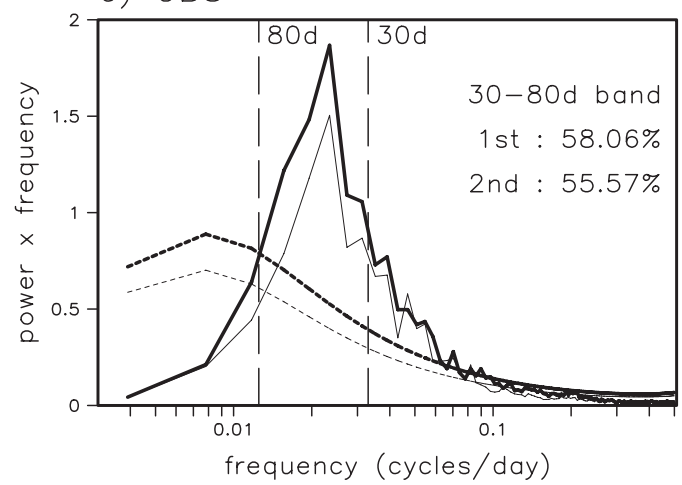

b) AR5a_Ent1

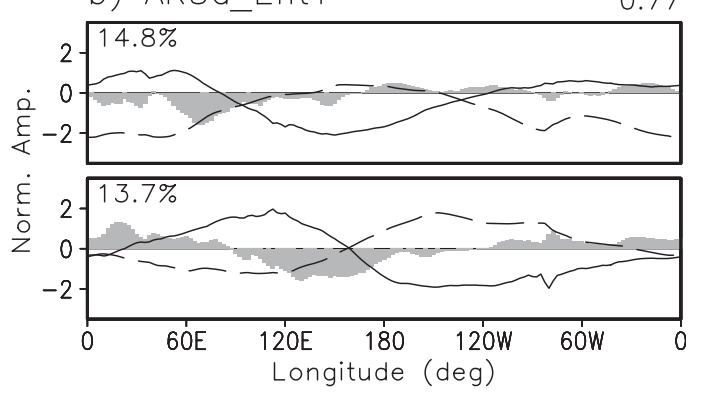

d) AR5a_Ent1

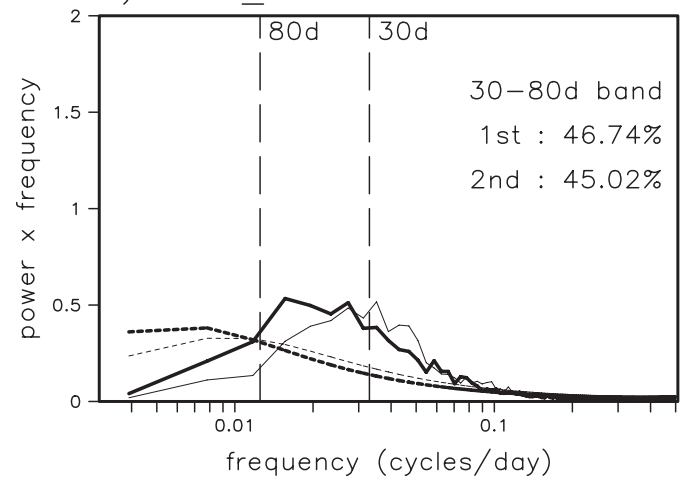

FIG. 6. First two CEOF modes of $20-100$-day $15^{\circ} \mathrm{S}-15^{\circ} \mathrm{N}$-averaged $850-\mathrm{hPa}$ (solid) and 200 -hPa (dashed) zonal wind and OLR (shaded contour) obtained from (a) observations and (b) AR5a_Ent1. The variance explained by each mode is shown in the upper left corner of each panel. The mean coherence squared between principal components of two modes within a 30-80-day period is given above the top panel. For AR5a_Ent1, the sign and location (upper or lower) of the mode are arbitrarily adjusted to be similar to observations. The mode having the largest percentage variance explained is the first mode. (c),(d) The power spectrum of the unfiltered PC derived by projecting the CEOFs onto unfiltered data (seasonal cycle removed): first mode (thick lines) and second mode (thin lines). The percentage of power residing within the 30-80-day band to the total in the spectrum is given in each panel. Dashed lines show the $99 \%$ confidence limit for a red noise spectrum.

a parameterization of convective organization into the GCM. Such an attempt has not been made in the context of Model E2. Rather, in this study, we choose one version, AR5a_Ent1, from our sensitivity experiments for further examination of the simulated MJO. We select AR5a_Ent1 for several reasons: it has the eastward/westward ratio closest to the observed value among all our simulations (Fig. 4) while having a smaller mean state bias than other strong-ISV versions (Fig. 5). Also, AR5a_Ent1 shows a Kelvin wave speed (Fig. 3) closer to the observed value than those in AR5a_Ent1_Re and AR5a_Ent2_Re.

\section{Analysis of the MJO simulated in a selected version of Model E2}

In this section, we investigate the characteristics of the MJO simulated in the experiment using AR5a_Ent1. The combined empirical orthogonal function (CEOF)MJO life cycle composite approach of Wheeler and Hendon (2004) is adopted for this purpose (Waliser et al. 2009; Kim et al. 2009). Using this method, the MJO is extracted as the dominant mode of intraseasonal variability using outgoing longwave radiation and zonal wind at 850 and $200 \mathrm{hPa}$. Figure 6 shows the first two CEOF modes of $20-100$-day $15^{\circ} \mathrm{S}-15^{\circ} \mathrm{N}$ averaged $850-\mathrm{hPa}$ and 200-hPa zonal wind and OLR from observations and the AR5a_Ent1 simulation. The MJO mode extracted from AR5a_Ent1 (Fig. 6b) captures the gross features of the leading modes in observations (Fig. 6a), such as the location of the maximum in convection (minimum OLR), baroclinic wind structure, and planetary spatial scale. The fractional variance explained by the MJO mode (sum of variances explained by the first and second modes) is about $29 \%$, which is smaller than that observed (about $44 \%$ ). To investigate the frequency of the MJO we constructed unfiltered principal components (PCs) by projecting the CEOFs onto unfiltered anomalies and then calculating power spectra of the resulting time series (Waliser et al. 2009). The power spectrum of the unfiltered PC shows that the MJO extracted by the CEOF has spectral peaks near the observed MJO time scale that are physically meaningful and distinct from a red noise process. 

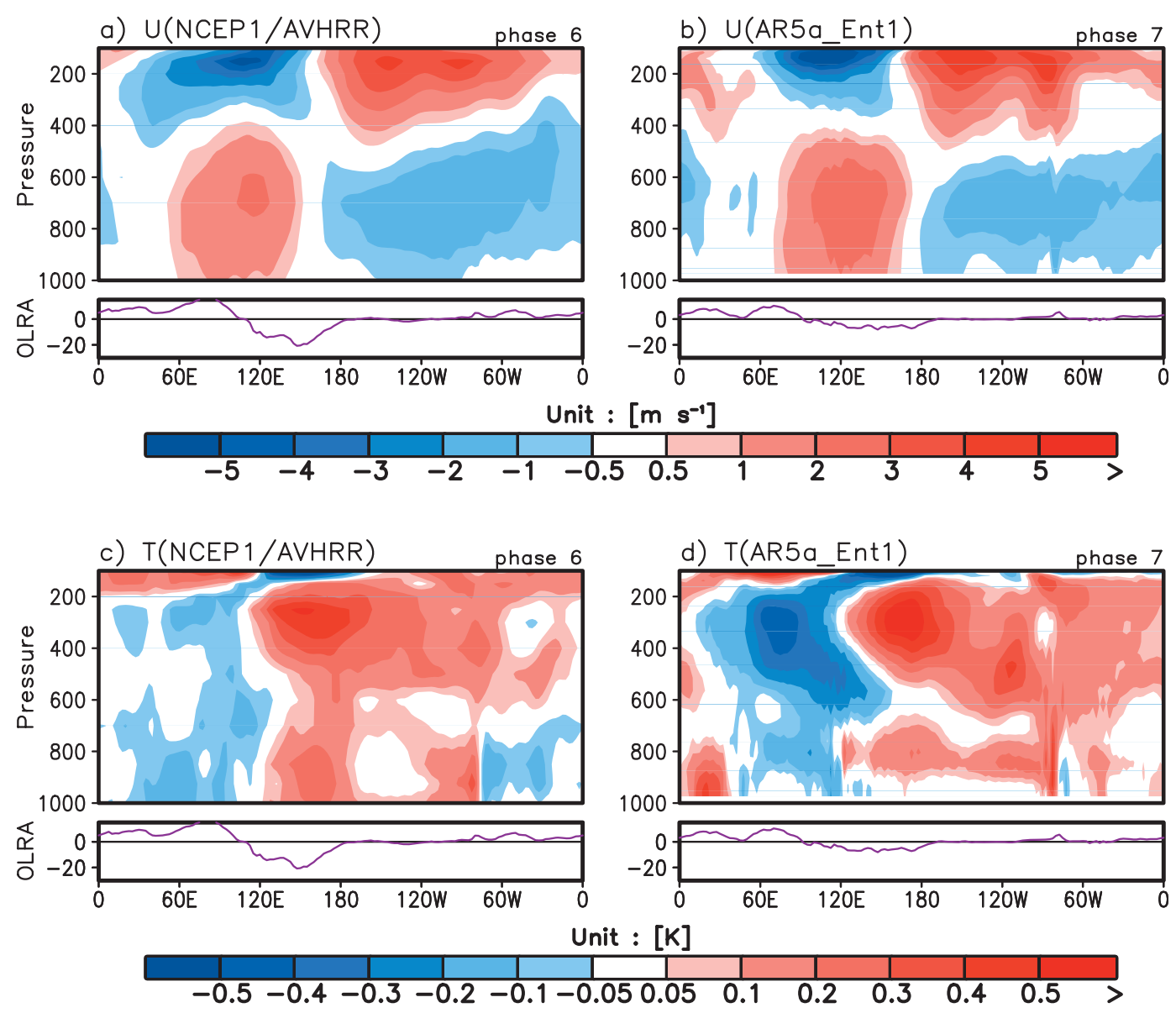

FIG. 7. MJO life cycle composite of 20-100-day bandpass filtered, $10^{\circ} \mathrm{S}-10^{\circ} \mathrm{N}$-averaged (a), (b) zonal wind ( $\mathrm{m} \mathrm{s}^{-1}$ ) and (c), (d) temperature (K) anomalies at different phases in which the convective anomaly is located near the western Pacific. The filtered $10^{\circ} \mathrm{S}-10^{\circ} \mathrm{N}$-averaged OLR anomaly $\left(\mathrm{W} \mathrm{m}^{-2}\right)$ of the corresponding phase is shown in the bottom panel of (a), (c) NCEP1/AVHRR and (b), (d) AR5a_Ent1.

The MJO life cycle composites of various variables are constructed using PCs from the CEOF to examine the physical structure of the simulated MJO. The MJO life cycle composite of a variable for a specific MJO phase is constructed by averaging 20-100-day filtered anomalies on the days when PCs indicate that the MJO is in that phase with strong enough amplitude (Wheeler and Hendon 2004). The phase of the MJO directly links to the location of the anomalous convection. For example, Fig. 7 shows composites of tropospheric zonal wind and temperature anomalies in a longitude-height diagram when the MJO-related convection is located near the west Pacific. It is phase 7 in the model, while it is phase 6 in observations (because we use the model's own CEOFs and its PCs to construct the MJO life cycle composite, the MJO phase corresponding to a specific location of enhanced convection can be different in the model from that in observations). AR5a_Ent1 exhibits a deep baroclinic structure in the zonal wind field similar to that in observations. The structure of composited temperature is also similar to observations, showing upper-level warming near the anomalous convective region and cooling below. The upper-tropospheric cool anomaly over the Indian Ocean is stronger in the model than in observations.

Figure 8 shows MJO life cycle composites of tropospheric specific humidity anomalies. Here we pick up three phases during which MJO-related convection moves from the Maritime Continent to the western Pacific. In observations, there is a signature of moisture preconditioning ahead (east) of current deep convection, which is well captured by AR5a_Ent1. The moisture anomaly simulated in AR5a_Ent1, however, shows a distinct minimum near $850 \mathrm{hPa}$, which is not observed. Other diagnostics suggest that the minimum is due to overactive shallow convection. The moisture preconditioning might be a mechanism for eastward propagation, as it leads the convective signal.

To examine the source of the boundary layer moisture preconditioning, MJO life cycle composites of surface 

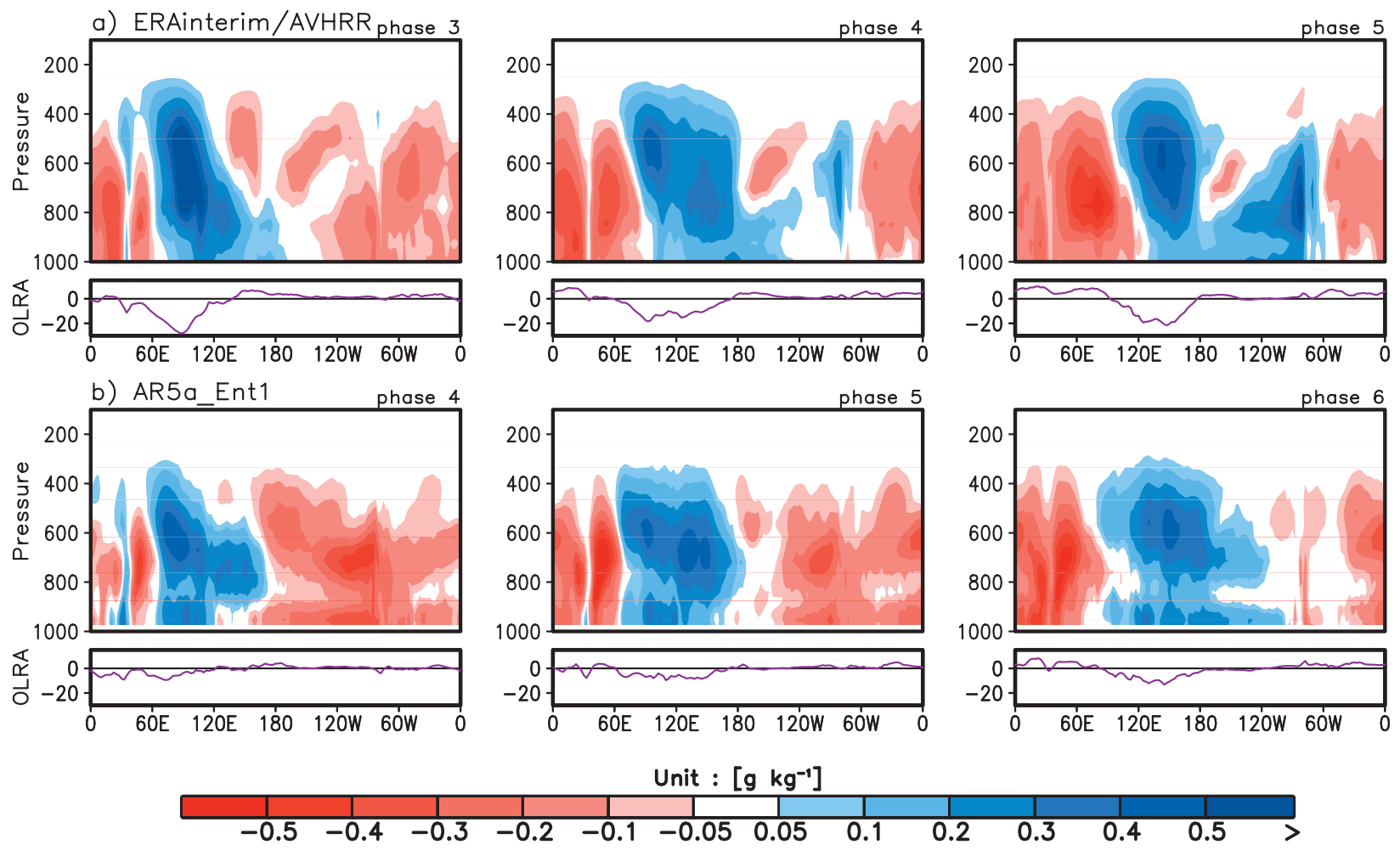

FIG. 8. MJO life cycle composite of $20-100$-day bandpass-filtered, $10^{\circ} \mathrm{S}-10^{\circ} \mathrm{N}$-averaged specific humidity anomaly $\left(\mathrm{g} \mathrm{kg}^{-1}\right.$, upper panel) and filtered, $10^{\circ} \mathrm{S}-10^{\circ} \mathrm{N}$ averaged OLR anomaly ( $\mathrm{W} \mathrm{m}^{-2}$, lower panel) for phase 3 to 5 in which the convective anomaly is located near the Indian Ocean and Maritime Continent for (a) ERA-Interim/AVHRR and (b) AR5a_Ent1.

evaporation and 925-hPa moisture convergence are constructed (Fig. 9). The contours in Fig. 9 show the OLR anomaly, which represents eastward propagation of MJO convection. In observations, the surface evaporation has a negligible contribution to the moisture preconditioning, while the maximum surface evaporation slightly lags the MJO convection, but by less than 90 degrees of phase so that the two fields are correlated with each other. This suggests that positive latent heat flux anomalies play a role in supporting the anomalous convection. In the model, the phasing between surface evaporation and OLR anomalies differs significantly from those in observations. In particular, there is a significant region of negative evaporation anomalies coincident with negative OLR anomalies in the Maritime Continent region, suggesting damping of the convective signal by surface fluxes. There is also a substantial region of negative evaporation anomaly that leads negative OLR in the Pacific. In observations, this would be coincident with positive boundary layer moisture anomaly during phases 3 and 4, the buildup to the active phase in the Pacific (Fig. 8a); the negative evaporation anomaly in the model may be partly responsible for the weaker moisture buildup in the model MJO during its equivalent phases 4 and 5 (Fig. 9b). On the other hand, both observed and simulated boundary layer moisture convergence slightly lead the convection anomaly during its passage (Figs. 9c and 9d). In summary, the moisture preconditioning simulated in AR5a_Ent1 (Fig. 8) is supported by boundary-layer moisture convergence as in observations, while the contribution from surface evaporation is negative and is different from that in observations.

\section{Reinitialization experiments}

In the previous section, it is shown that the MJO simulated in AR5a_Ent1 has physical structures that compare qualitatively well to observations in various respects. To better understand the improvement in the MJO simulation that is achieved in AR5a_Ent1 against AR5a, a series of 30-day integrations is performed with AR5a using multiple initial conditions from AR5a_Ent1. Figure 10 shows a schematic of the reinitialization experiment. Using this experimental framework we aim to diagnose the source of the difference between the two versions. In particular, we will focus on the effect of the changes in cumulus parameterization on the large-scale organization of tropical convection. For the experiments, a strong-MJO event is depicted from the 20-yr integration of AR5a_Ent1. In Fig. 11a the selected MJO-like disturbance is shown in 

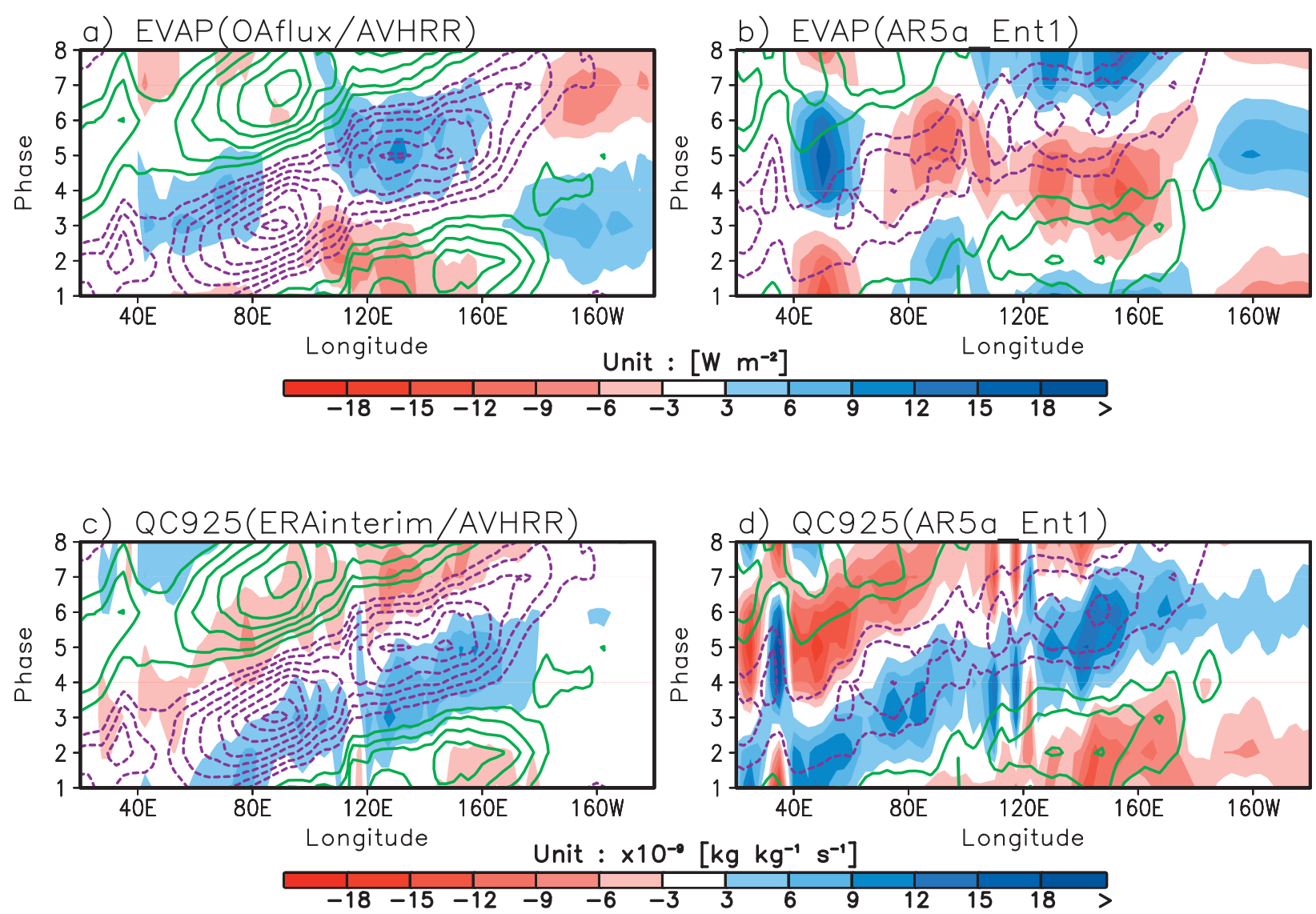

FIG. 9. Phase-longitude diagram of OLR [contour plotted every $3 \mathrm{~W} \mathrm{~m}^{-2}$, positive (green) and negative (purple)] and surface evaporation $\left(\mathrm{W} \mathrm{m}^{-2}\right) / 925-\mathrm{hPa}$ moisture convergence $\left(\mathrm{kg} \mathrm{kg}^{-1} \mathrm{~s}^{-1}\right)$ for (a), (c) observations, and (b), (d) AR5a_Ent1. Phases are from the MJO life cycle composite; values are averaged between $10^{\circ} \mathrm{S}$ and $10^{\circ} \mathrm{N}$.

a 2D phase space of the two leading PCs from the CEOF analysis. In this $2 \mathrm{D}$ phase space, distance from the origin represents amplitude of the MJO. The strong-MJO event occurs during March-April 2000 in the simulation. Hovmöller diagrams of total, anomalous (deviations from the seasonal cycle) and 20-100-day filtered equatorial $\left(15^{\circ} \mathrm{S}-15^{\circ} \mathrm{N}\right)$ precipitation show the eastward propagation of organized precipitation anomalies with phase speed $\sim 5 \mathrm{~m} \mathrm{~s}^{-1}$ during this period (Fig. 11). Daily restart files are saved during the period of this event and used to initialize the 30-day integrations of AR5a. Note that we use restart files during February-May 2000 to encompass the whole strong-MJO period.

During the course of the 30-day integration, the AR5a version systematically deviates from the AR5a_Ent1 version. Figure 12a shows the composite deviations of the tropospheric temperature from the first day of simulation. It indicates that the tropical atmosphere becomes stabilized (warmer upper/colder lower troposphere) gradually until day 30. The warming aloft is greater than the cooling below so that the mass-weighted average of tropospheric temperature increases (Fig. 12b). The relative humidity (Fig. 12c) and precipitable water (Fig. 12d) also increase. These systematic changes caused by the decreasing entrainment rate (from AR5a_Ent1 to AR5a) can be characterized as enhanced stability in the tropics. This result is consistent with those of Kim et al. (2011b), who showed that models with stronger MJOs also had a cold bias in the upper troposphere relative to

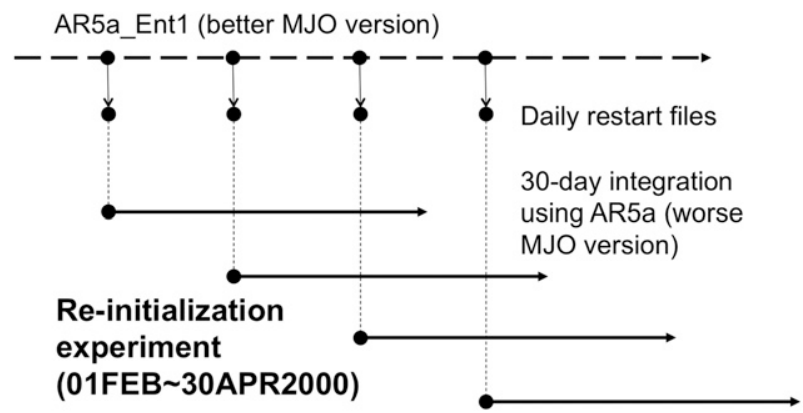

FIG. 10. Schematic diagram of the reinitialization experiment. 


\section{a) $20 \mathrm{Feb} 2000-12 \mathrm{Apr} 2000$}

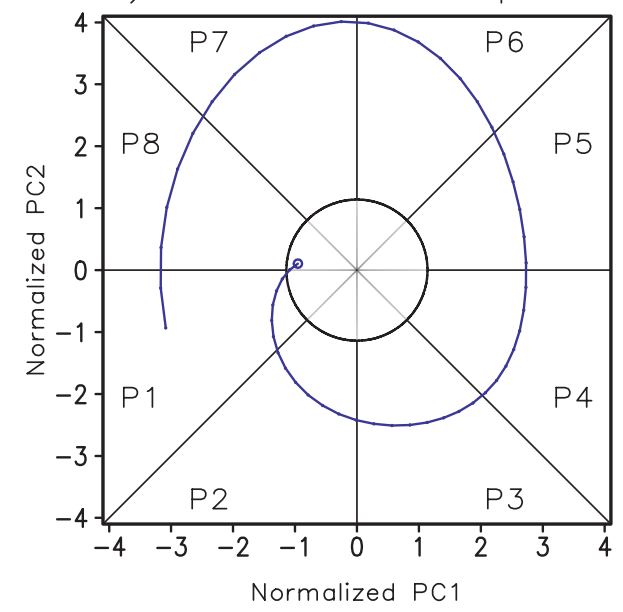

c) Anomaly

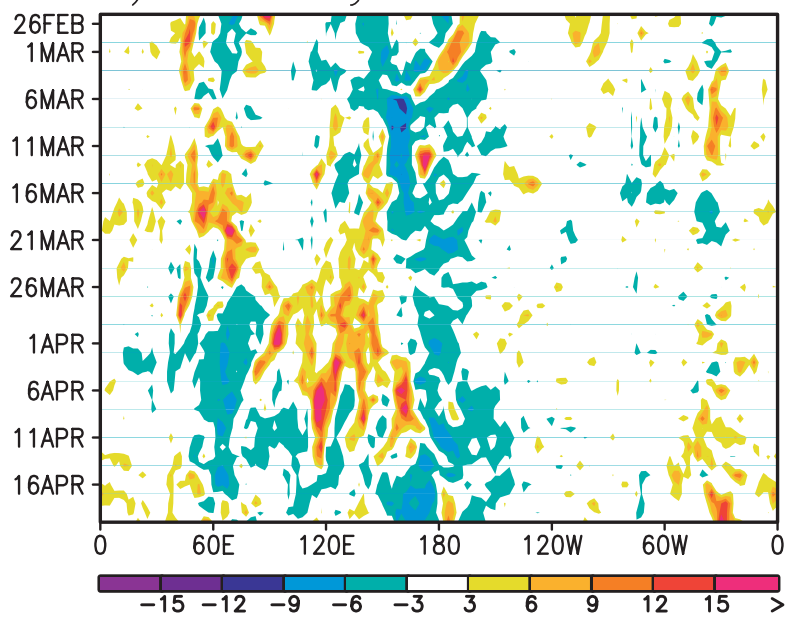

b) Total

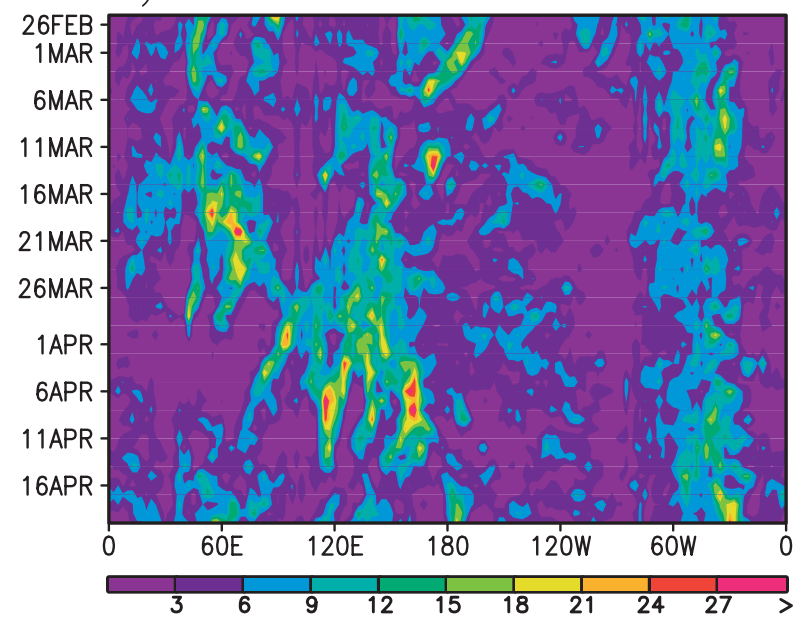

d) 20-100day filtered

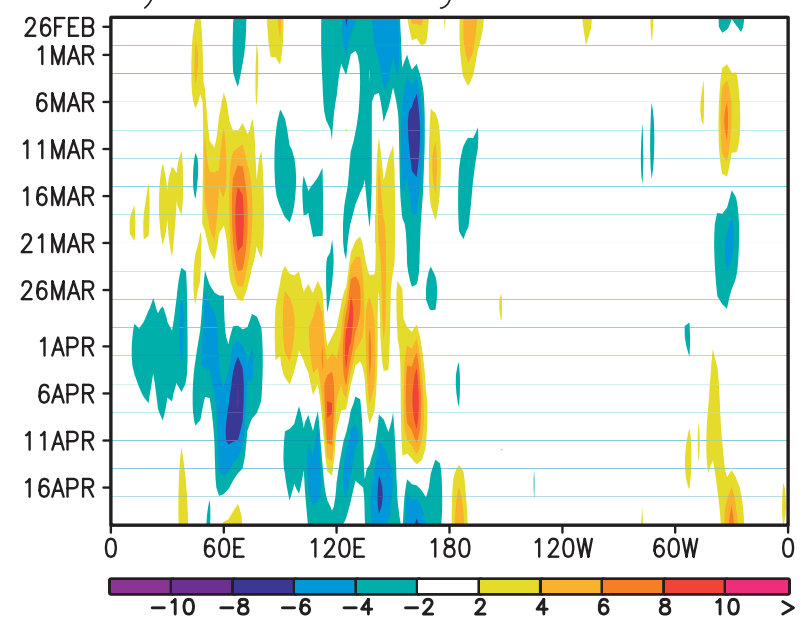

FIG. 11. (a) Phase diagram of PCs from CEOF during the strong-MJO event: (b) total, (c) anomaly, and (d) 20-100-day filtered precipitation during the strong-MJO event. Precipitation is averaged between $15^{\circ} \mathrm{S}$ and $15^{\circ} \mathrm{N}$.

those with weaker MJOs. The systematic change in stability of the tropical atmosphere in response to the change in entrainment rate has also been documented in other models (Mapes and Neale 2011).

In Fig. 13 Hovmöller diagrams of equatorial precipitation are plotted, representing the sequences of the pattern during the 30-day integration. Figure 13a displays rainfall simulated using AR5_Ent1 in the period of the selected strong-MJO event. Figures $13 \mathrm{~b}$ and $13 \mathrm{c}$ are corresponding plots constructed by collecting the data after 10 and 20 days from initialization. Therefore, for example, the data used to plot Figs. 13b is not from a single 30-day integration; each day of data is from multiple 30-day integrations. We use the AR5a simulation to construct Fig. 13d, which we can regard as an infinite-day-afterinitialization version. Therefore, from left to right we see how changes in the convection scheme alter the distribution of convection in the tropics. In AR5a_Ent1, tropical convection organizes into planetary-scale supercloud clusters and the organized convection moves eastward (Fig. 13a). Here the organization is roughly defined in the Hovmöller diagram as the formation of closely located strong rainfall blobs. After 10 days from initialization there are still some organized, eastward propagating features, but they are much less prominent than those simulated using AR5a_Ent1 (Fig. 13b). In Fig. 13c, after 20 days the $2 \mathrm{~mm}$ day $^{-1}$ contour covers the whole tropics, making the pattern diffuse. The signature of organization as in AR5a_Ent1 is hardly seen after this point.

In Fig. 13e, it is shown that the fractional area covered by grid points where the rain rate is greater than $10 \mathrm{~mm}$ day $^{-1}$ increases immediately after initialization. This instant response to the reduced entrainment rate means that the tropics are more occupied by convecting columns, 
a) $T$ deviation $(K)$

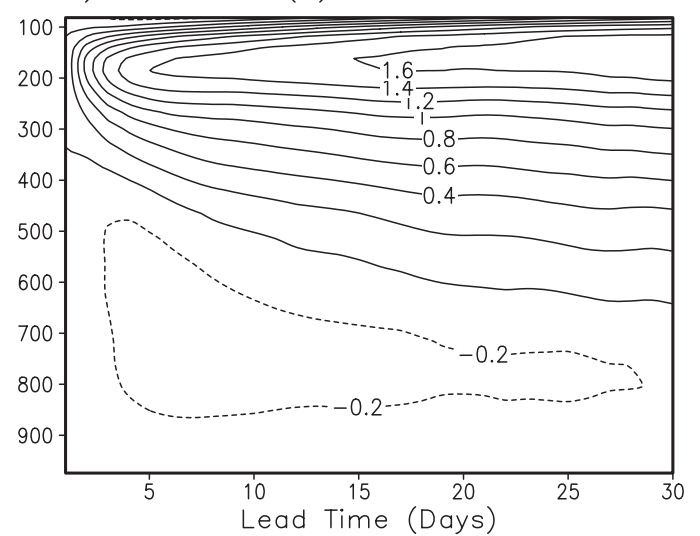

c) $\mathrm{RH}$ deviation (\%)

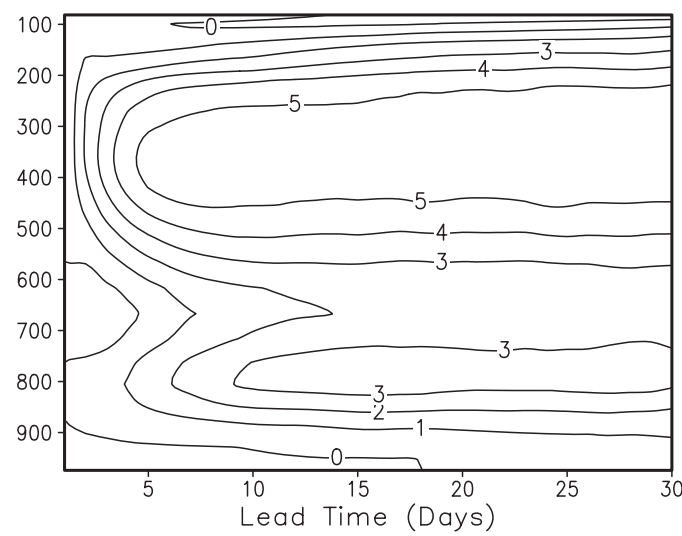

b) $\mathrm{T}(1000-100 \mathrm{hPa})(\mathrm{K})$

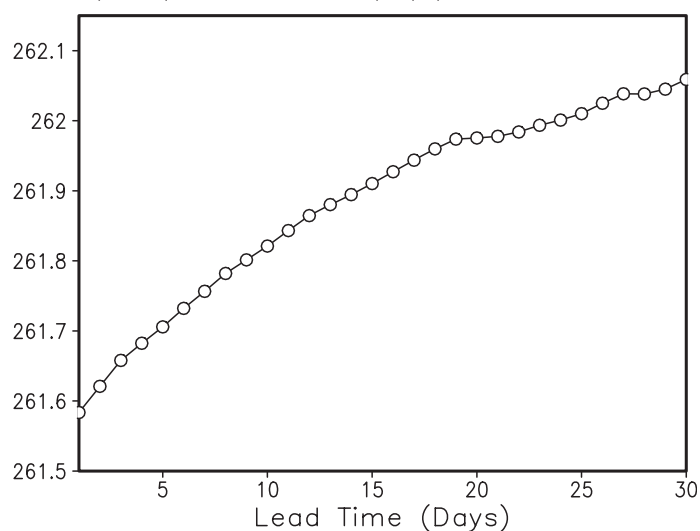

d) Precipitable Water $(\mathrm{mm})$

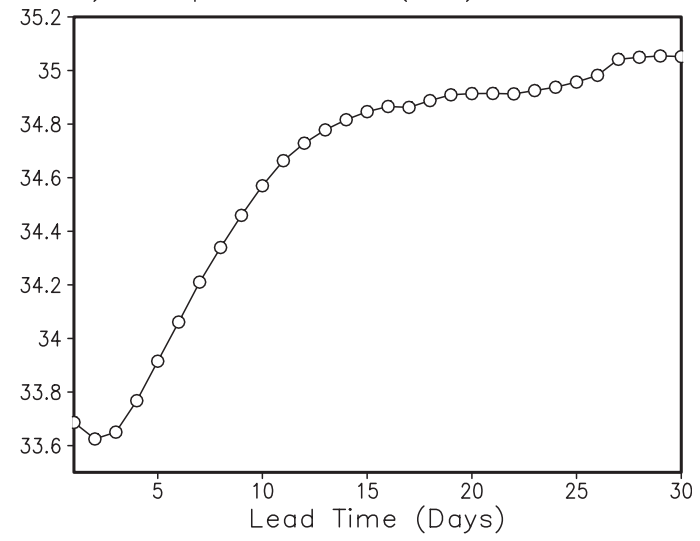

FIG. 12. Pressure vs lead time plot of deviation (a) temperature (K) averaged over $30^{\circ} \mathrm{S}-30^{\circ} \mathrm{N}, 0^{\circ}-360^{\circ}$ and (c) relative humidity (\%) from the first-day mean. (b) Mass-weighted average temperature (K), and (d) tropicsaveraged precipitable water $(\mathrm{mm})$ during the 30 -day integrations.

decreasing the possibility of losing buoyancy due to mixing with subsaturated environmental air. After the initial increase, the fractional area remains without much variation except for a small further increase in between the values found in AR5a and AR5a_Ent1 (Fig. 13e). To measure the degree of organization, we calculated a mean distance between any two grid points with rain rate greater than $10 \mathrm{~mm}$ day $^{-1}$. When this number is large, it means convecting grids are spread over the globe, while the number will decrease as the convecting grids organize. Our calculation shows that the mean distance in AR5a is greater than that of AR5_Ent1 (Fig. 13f). At the time of initialization the mean distance is close to that of AR5_Ent1 and increases with lead time of the 30-day integration approaching the value of AR5a.

The increase of the fractional area covered by deep convection and the increase of mean distance between convecting grid points are both direct consequences of reducing the entrainment rate. These affect the organization of tropical convection in the model, as seen in the Hovmöller diagrams. Convective organization can be defined as the occurrence of deep convection selectively in some preferred area. By allowing deep convection to occur more easily in widespread regions, the reduced entrainment rate suppresses the organization of tropical convection. Figure $13 \mathrm{~g}$ shows that the pattern correlation of tropical precipitation between the 30-day reinitialization experiments and their counterparts in the AR5a_Ent1 simulation drops to less than 0.5 within eight days from initialization. The correlation drops more quickly if we compute the pattern correlation only over a warm pool domain $\left(15^{\circ} \mathrm{S}-15^{\circ} \mathrm{N}, 40^{\circ} \mathrm{E}-180^{\circ}\right.$; not shown), suggesting that the changes in the convectively active region dominate the drop of pattern correlation. This illustrates how reducing the entrainment rate disorganizes tropical convection and thereby degrades the MJO.

Figure 14 demonstrates how reduced entrainment destroys the organization by showing the change in the local moisture-convection relationship during the initial period of the serial integrations. The shading in Fig. 14 represents composited pressure velocity and diabatic heating rate based on precipitable water over the warm 
a) AR5a_Ent1

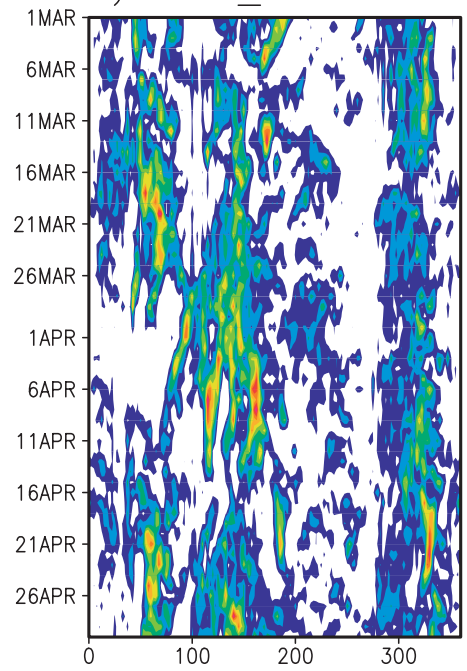

b) Lead day: 10

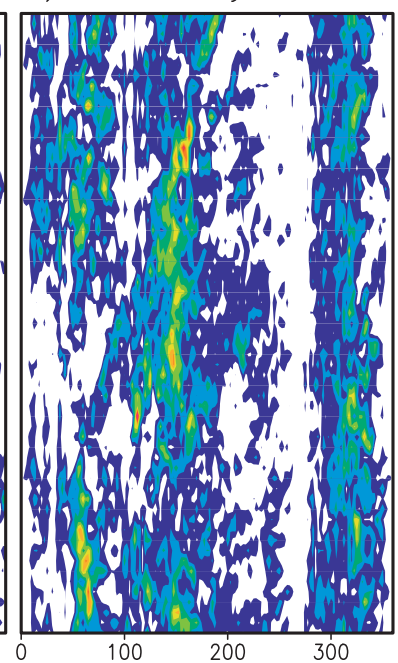

c) Lead day: 20

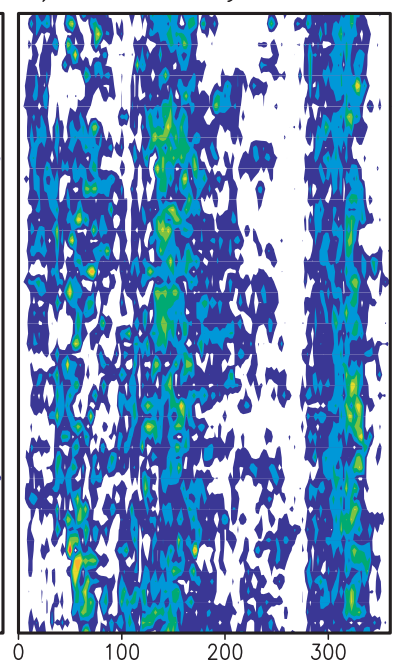

d) AR5a

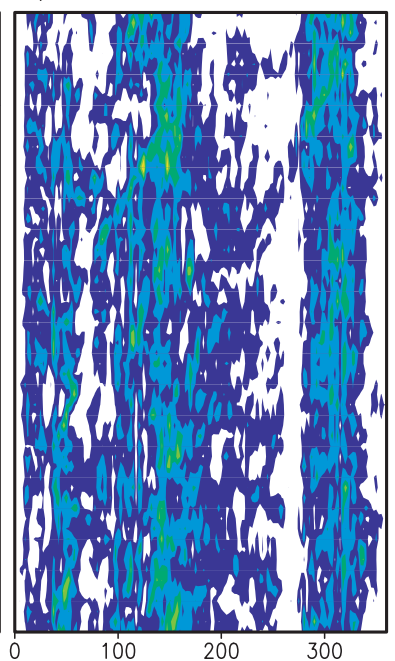

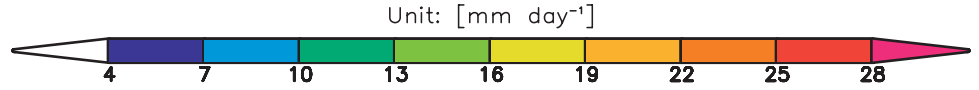

e) Fractional area

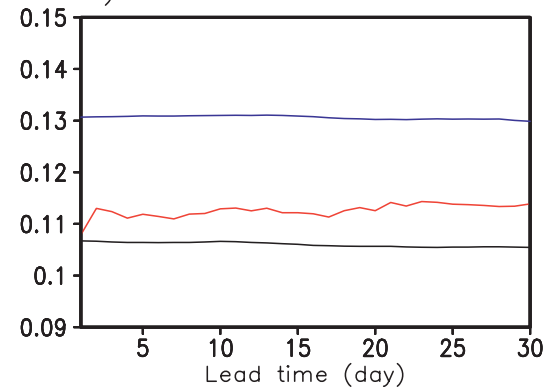

f) Mean distance $(\mathrm{km})$

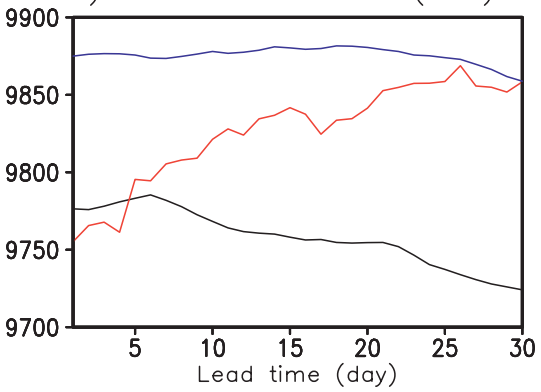

g) Pattern correlation

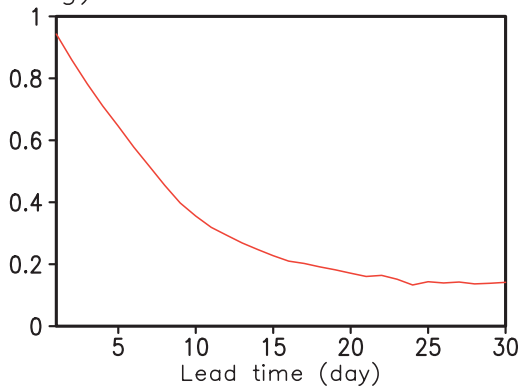

FIG. 13. Hovmöller diagram of $15^{\circ} \mathrm{S}-15^{\circ} \mathrm{N}$-averaged precipitation during the strong-MJO period selected based on the MJO phase diagram for (a) AR5a_Ent1, (b) 10-day and (c) 20-day after reinitialization, and (d) AR5a. (e) Fractional area of the grid points with precipitation greater than $10 \mathrm{~mm}$ day $^{-1}$ as a function of lead time; all grid points in the tropics $\left(30^{\circ} \mathrm{S}-30^{\circ} \mathrm{N}, 0^{\circ}-360^{\circ}\right)$ are used in the calculations. (f) Mean distance between any two grids with rain rate greater than $10 \mathrm{~mm} \mathrm{day}^{-1}$. (g) Pattern correlation between tropical precipitations of 30-day reinitialization experiments and their counterpart in AR5a_Ent1 simulation as a function of lead time. In (e) and (f) red line represents result from the 30-day reinitialization experiments, while black and blue lines represent AR5a_Ent1 and AR5a simulations, respectively.

pool region (ocean only). Note that we use data from the AR5a_Ent1 simulation for the period of the strongMJO event to construct Fig. 14. The composites show rising motion in moist columns and sinking motion in dry columns, representing a notional overturning circulation between them. This overturning circulation is maintained by the differential diabatic heating rate shown in Fig. 14b; diabatic heating preferentially occurs in the moist columns. For this plot we use grid points over the warm pool $\left(15^{\circ} \mathrm{S}-15^{\circ} \mathrm{N}, 40^{\circ} \mathrm{E}-180^{\circ}\right)$ where the surface temperature is highest and the convection is the most active in the world. We regard here the strength of the overturning circulation in the composite plot as a proxy for the degree of organization.
Next we collect only the first days from the reinitialization experiments and subtract the results of the corresponding AR5a_Ent1 simulations from them. The difference calculated in this way reflects the nearinstantaneous impact of decreasing entrainment rate. The deviations of pressure velocity and diabatic heating rate are composited based on AR5a_Ent1 precipitable water (Fig. 14, contours). Figure 14b shows that anomalous deep convection quickly (within one day) develops after changing the parameterization, especially in the regime of precipitable water: $35-45 \mathrm{~mm}$. This might contribute to the increase of the convecting area (Fig. 13e). This also means that the activation of deep convection in this region is suppressed in AR5a_Ent1 due to the larger 

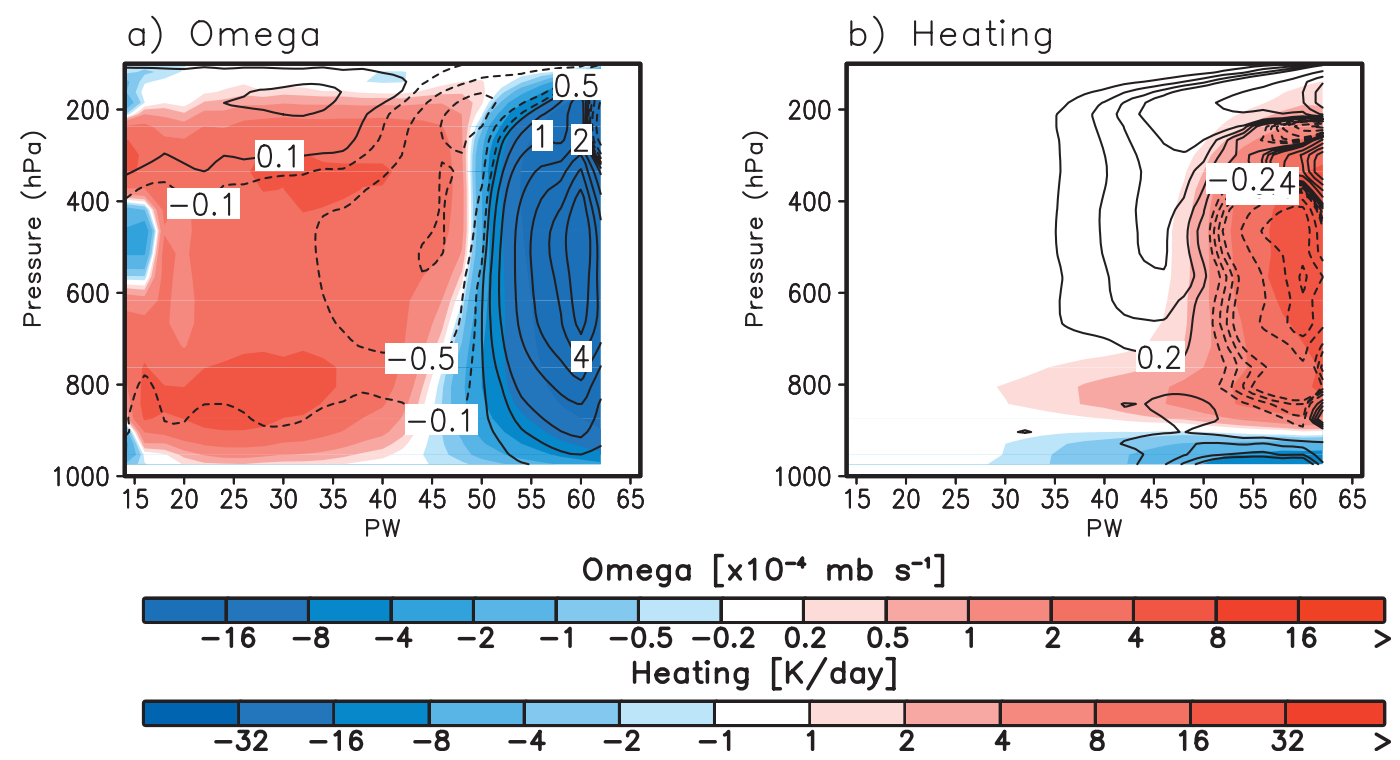

FIG. 14. Composited (a) pressure velocity $\left(\mathrm{mb} \mathrm{s}^{-1}\right)$ and (b) diabatic heating rates $\left(\mathrm{K} \mathrm{day}^{-1}\right)$ of the AR5a_Ent1 simulation (shaded) based on precipitable water. Contours in (a) and (b) show the first-day deviation of the reinitialization experiment from AR5a_Ent1, composited based on same precipitable water.

entrainment rate. At the same time, diabatic heating in the moist columns decreases, making the differential heating between wet and dry columns smaller. The reduced differential heating results in weakening of the overturning circulation, as shown in Fig. 14a; both rising and sinking motions weaken. The weakening of the overturning circulation implies less-organized tropical convection and a poor MJO, as seen in Fig. 13. This result suggests that the strengthening of the local moistureconvection relationship (i.e., depth and strength of convection more strongly depends on column-integrated moisture amount) is one of the reasons for the improvements in the simulation of the MJO in Model E2.

\section{Impacts on tropical cyclone activity}

Since the 1970s (Manabe et al. 1970; Bengtsson et al. 1982) many studies have shown that low-resolution climate models are able to simulate TC-like disturbances that have properties similar to those of observed TCs, but are typically weaker and larger in horizontal scales. As the resolution of the models increases, the simulation of TCs becomes more realistic (Bengtsson et al. 1995). While low-resolution simulations of climate models are not adequate to simulate individual TCs tracks and intensities, these models are able to reproduce a number of qualitative aspects of seasonal TC activity. For instance, they are able to reproduce typical ENSO influences on TC activity (Vitart et al. 1997) and have been used to produce dynamical seasonal forecasts of TCs (Camargo and Barnston 2009). These models are also widely used in climate change studies to infer changes in TC activity in a future climate (e.g., Bengtsson et al. 1996; Krishnamurti et al. 1998; Tsutsui 2002). It is therefore of interest to investigate the climatological properties of TC-like structures in climate models. Although some biases occur for all models-presumably as a result of low resolution- others are model dependent (e.g., Camargo et al. 2005).

Here we examine the properties of TC-like structures in the GISS models at low resolution. We are particularly interested in how the TC activity in the model is influenced by changes in convection scheme and how this may be related to the MJO changes in the model. While the results must at this point be interpreted as relevant only to this one model, it is possible that they may be of broader significance. We are not aware of other studies simultaneously examining the response of TC-like vortices and other tropical disturbances to changes in convective parameterization, so perhaps - as is the case with the MJO sensitivity to convective physics - what we find here may also hold in other models. In addition, to our knowledge, this is the first time that the TC activity in any version of the GISS GCM has been examined.

To detect and track TC-like structures in the Model E2 simulations we used the algorithm described in Camargo and Zebiak (2002). Using the 6-hourly model output, we localize structures with a local minimum sea level pressure, local maximum vorticity $(850 \mathrm{hPa})$ and wind speed, and a warm core. We use thresholds for these local maxima and minima based on the model statistics. For example, over the western North Pacific 
(a) AR5a

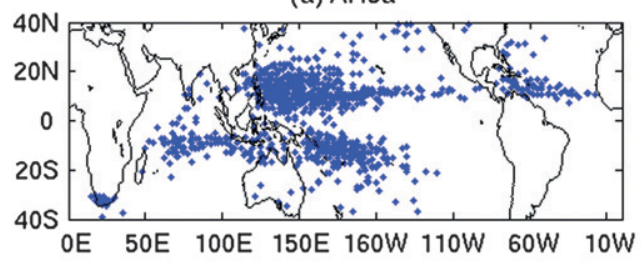

(c) AR5a_Ent1

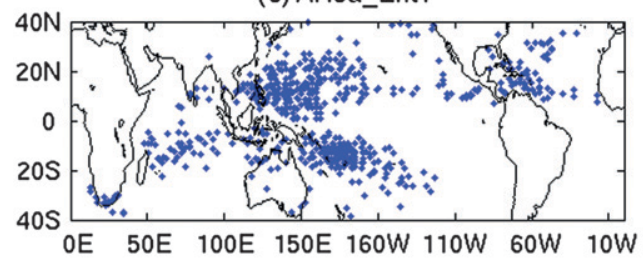

(e) AR5a_Ent1_Re

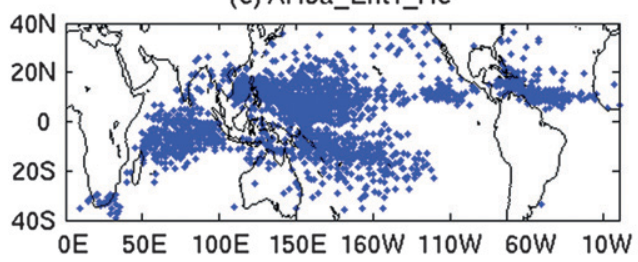

(g) Observations

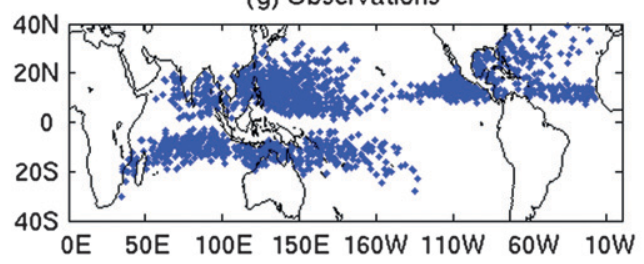

(b) AR5a

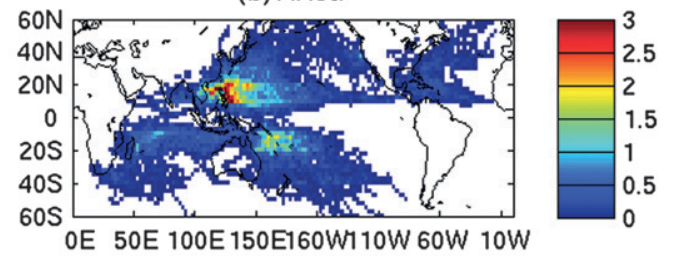

(d) AR5a_Ent1

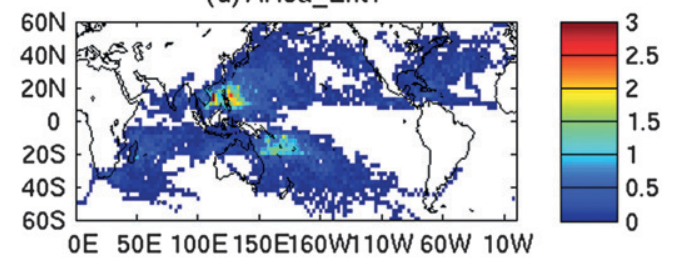

(f) AR5a_Ent1_Re

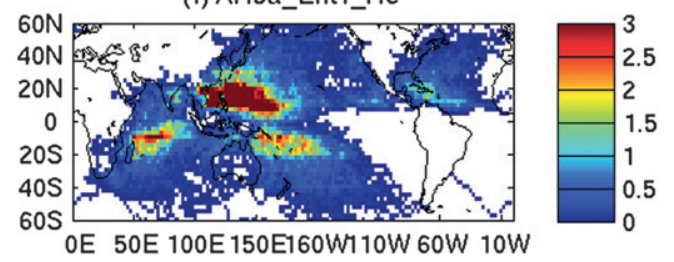

(h) Observations

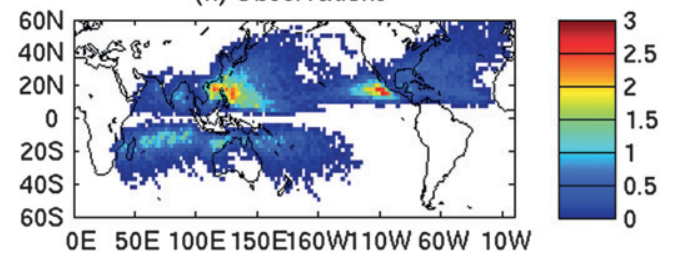

FIG. 15. (left) The initial positions and (right) track density of all tropical cyclones during 1989-2008 for (top to bottom) AR5a, AR5_Ent1, AR5_Ent1_Re, and observations.

the specific values of the thresholds are $3.8 \times 10^{-5} \mathrm{~s}^{-1}$ for vorticity, $9.2 \mathrm{~m} \mathrm{~s}^{-1}$ for wind speed, and $2.3^{\circ} \mathrm{C}$ for the local temperature anomaly. The thresholds depend on the basin, but the difference between values for different basins are small. Once all of the conditions are satisfied, the cyclones are tracked using the low-level vorticity. Figure 15 shows the first positions and track density (number of times a TC passes by a grid point) for the TCs in AR5a (top), AR5a_Ent1 (second row), AR5a_Ent1_Re (third row), and observations (bottom) for the period 1989-2008. Overall, the regions of $\mathrm{TC}$ formation correspond to those in observations to a degree roughly typical of other low-resolution climate models (see, e.g., Camargo et al. 2005).

Closer examination reveals significant deficiencies. There are very few model TCs in the eastern North Pacific, a bias commonly present in many low-resolution models. In the AR5a model, there is also apparent formation of TCs on the coast of California and South Africa, a phenomenon which has no counterpart in the observations. The formation of storms over Australia is an interesting characteristic of this model, as land formation is not observed in other regions of the world (with the exception of very near the coastlines, which could probably be improved by tuning the track algorithm). In the Southern Hemisphere the model is more active in the South Pacific than in the south Indian Ocean, while in observations the reverse is the case. Finally, the Southern Hemisphere storm tracks tend to go farther toward the poles than in observations, which could be due to differences in the thresholds on tracking storms in observations and in the model.

In the three versions of the model, overall, the distribution of genesis location and the pattern of track density are similar to each other. The number of TC-like vortices (NTC), however, varies significantly from one version to another. In AR5a_Ent1 the NTC is lower than that in AR5a. This suggests that increasing the entrainment rate weakens TC-like vortex activity. On the other hand, when we allow more rain reevaporation in AR5a_Ent1 (AR5a_Ent1_Re), the NTC dramatically increases in the model. We analyzed large-scale variables (e.g., vorticity, 
vertical shear) in the AR5a and AR5a_Ent1 versions and found no significant differences between the simulations in the large-scale environmental variables believed most relevant for genesis (not shown). These results strike us as interesting. In the case of varying entrainment rate, changes to the convective parameterization that strengthen the MJO inhibit formation of the TC-like vortices; however, in the case of varying rain reevaporation, the response of the MJO and TC-like vortices is in the same sense. We do not understand these results at present nor do we know if they will generalize to other models. If they do, understanding the physics behind them would seem to be a worthy goal.

\section{Summary and conclusions}

In this study, we have examined the tropical subseasonal variability simulated in several versions of the atmospheric component of the NASA GISS GCM Model_E2, which is being used for the IPCC AR5. The AR5 version of Model_E2 is superior to its ancestor-Model_E-in terms of the magnitude of intraseasonal variability and the amplitude and phase speed of convectively coupled Kelvin waves. Despite these improvements, the AR5 version still lacks the MJO mode, which dominates intraseasonal variability over the tropics and interacts with various other climate components in nature.

Consistent with previous studies (Maloney and Hartmann 2001; Lee et al. 2003; Lin et al. 2008), simulation of the MJO was found to depend on cumulus parameterization. By tuning the convective scheme to have a greater entrainment rate and more rain reevaporation, we were able to simulate the MJO with a fidelity typical of other models similarly tuned to strengthen their MJO simulations, but at a cost of mean state biases, also typical of such models (Kim et al. 2011b). Based on the overall magnitude of tropical intraseasonal variability, mean state, and equivalent depth of the tropical atmosphere we selected one version (AR5a_Ent1) from the set of sensitivity experiments to investigate the MJO in that simulation.

We used a CEOF approach (Wheeler and Hendon 2004) to extract the MJO mode-defined here as the leading mode of coherent variability between anomalies of upper- and lower-tropospheric zonal wind, and convection, from observations and AR5a_Ent1 simulations. The leading pair of CEOFs in AR5a_Ent1 capture the gross features of the leading mode in observations, such as the location of the maximum in convection (minimum OLR), baroclinic wind structure, and planetary spatial scale. The power spectrum of the unfiltered PC showed that the MJO isolated by the CEOFs has spectral peaks near the observed MJO time scale that are physically meaningful and distinct from a red noise process.

The MJO life cycle composite constructed using PCs of the leading pair of CEOFs showed that the MJO simulated in AR5a_Ent1 has structures that compare qualitatively well to observations in various respects such as the structures of zonal wind, temperature, specific humidity, and the phase relationship between convection and $925-\mathrm{hPa}$ moisture convergence. In both observations and AR5a_Ent1, positive moisture anomalies in the lower troposphere develop ahead (east) of the convective anomaly related to the MJO. Anomalous 925-hPa moisture convergence leads the convective anomaly, suggesting its role in moistening the lower troposphere. The tropospheric moisture anomalies between 900 and $800 \mathrm{hPa}$ are not sufficiently coherent with those at other levels compared to observations.

By reinitializing a relatively poor $\mathrm{MJO}$ version (AR5a) with restart files from a relatively better MJO version (AR5a_Ent1), a series of 30-day integrations was performed to examine the impacts of the parameterization changes on the organization of tropical convection. During the course of the 30 days, the simulated tropical atmosphere deviates from the AR5a_Ent1 with a greater stability, a higher temperature, and higher precipitable water. At the same time the fractional area of convection expands, the mean distance between convecting grids increases, and the contrast between dry and wet regimes decreases, so that the tropical convection becomes diffuse and less organized. This suggests that the lack of an MJO in AR5a was partly due to the inadequate relationship between tropospheric moisture and precipitation (diabatic heating).

TC-like structures in the selected Model E2 simulations were analyzed. The regions of tropical cyclone formation correspond to those in observations to a degree roughly typical of other low-resolution climate models. The frequency of TCs in the model was affected by the changes in convection scheme, while the distribution of genesis location and the pattern of track density were similar in all versions. With the larger entrainment rate the model simulates a smaller number of TCs globally (AR5a_Ent1). By contrast, the number of TC-like vortices dramatically increases when we allow more rain reevaporation (AR5a_Ent1_Re). In the case of entrainment, the fact that a change in the parameterization that strengthens one form of convective organization (MJO) simultaneously weakens another (TCs) suggests that the parameterization flaws are likely structural rather than solvable by parameter tuning. On a practical level, it illustrates the conundrum faced by modelers in selecting the "best" physics for operational versions of GCMs and the need for further insight into these processes. 
Acknowledgments. This work was supported by NASA Grant NNX09AK34G, by the NASA Modeling andAnalysis Program model development RTOP at GISS, and by the NASA Precipitation Science Program. The ERA-Interim data used in this study have been provided by the ECMWF data server.

\section{REFERENCES}

Bechtold, P., M. Köhler, T. Jung, F. Doblas-Reyes, M. Leutbecher, M. J. Rodwell, F. Vitart, and G. Balsamo, 2008: Advances in simulating atmospheric variability with the ECMWF model: From synoptic to decadal time-scales. Quart. J. Roy. Meteor. Soc., 134, 1337-1351.

Bengtsson, L., H. Böttger, and M. Kanamitsu, 1982: Simulation of hurricane-type vortices in a general circulation model. Tellus, 34, 440-457.

—, M. Botzet, and M. Esch, 1995: Hurricane-type vortices in a general circulation model. Tellus, 47A, 175-196.

$\_, \ldots$, and — 1996: Will greenhouse gas-induced warming over the next 50 years lead to higher frequency and greater intensity of hurricanes? Tellus, $\mathbf{4 8 A}, 57-73$.

Bergman, J. W., H. H. Hendon, and K. M. Weickmann, 2001: Intraseasonal air-sea interactions at the onset of El Niño. J. Climate, 14, 1702-1719.

Bessafi, M., and M. C. Wheeler, 2006: Modulation of south Indian Ocean tropical cyclones by the Madden-Julian oscillation and convectively coupled equatorial waves. Mon. Wea. Rev., 134, 638-656.

Boyle, J., S. Klein, G. Zhang, S. Xie, and X. Wei, 2008: Climate model forecast experiments for TOGA COARE. Mon. Wea. Rev., 136, 808-832.

Camargo, S. J., and S. E. Zebiak, 2002: Improving the detection and tracking of tropical cyclones in atmospheric general circulation models. Wea. Forecasting, 17, 1152-1162.

— , and A. G. Barnston, 2009: Experimental seasonal dynamical forecasts of tropical cyclone activity at IRI. Wea. Forecasting, 24, 472-491.

— - - and S. E. Zebiak, 2005: A statistical assessment of tropical cyclone activity in atmospheric general circulation models. Tellus, 57A, 589-604.

—, M. C. Wheeler, and A. H. Sobel, 2009: Diagnosis of the MJO modulation of tropical cyclogenesis using an empirical index. J. Atmos. Sci., 66, 3061-3074.

Dee, D. P., and Coauthors, 2011: The ERA-Interim reanalysis: Configuration and performance of the data assimilation system. Quart. J. Roy. Meteor. Soc., 137, 553-597.

Del Genio, A. D., W. Kovari, M. S. Yao, and J. Jonas, 2005: Cumulus microphysics and climate sensitivity. J. Climate, 18, 2376-2387.

—, M.-S. Yao, and J. Jonas, 2007: Will moist convection be stronger in a warmer climate? Geophys. Res. Lett., 34, L16703, doi:10.1029/2007GL030525.

Gregory, D., 2001: Estimation of entrainment rate in simple models of convective clouds. Quart. J. Roy. Meteor. Soc., 127, 53-72.

$\ldots$ - R. Kershaw, and P. Inness, 1997: Parametrization of momentum transport by convection. II: Tests in single column and general circulation models. Quart. J. Roy. Meteor. Soc., 123, 1153-1183.

Holloway, C. E., and J. D. Neelin, 2009: Moisture vertical structure, column water vapor, and tropical deep convection. J. Atmos. Sci., 66, 1665-1683.
Huffman, G. J., R. F. Adler, M. M. Morrissey, D. T. Bolvin, S. Curtis, R. Joyce, B. McGavock, and J. Susskind, 2001: Global precipitation at one-degree daily resolution from multisatellite observations. J. Hydrometeor., 2, 36-50.

Kalnay, E., and Coauthors, 1996: The NCEP/NCAR 40-Year Reanalysis Project. Bull. Amer. Meteor. Soc., 77, 437-471.

Kärcher, B., and U. Lohmann, 2002: A parameterization of cirrus cloud formation: Homogeneous freezing of supercooled aerosols. J. Geophys. Res., 107, 4010, doi:10.1029/2001JD000470.

Kessler, W. S., 2001: EOF representations of the Madden-Julian oscillation and its connection with ENSO. J. Climate, 14, 30553061.

Kim, D., and Coauthors, 2009: Application of MJO simulation diagnostics to climate models. J. Climate, 22, 6413-6436.

_ A. D. Del Genio, and M.-S. Yao, 2011a: Moist convection scheme in Model E2. NOAA Tech. Note, 9 pp. [Available online at http://www.giss.nasa.gov/tools/modelE/docs/kim moistconvection.pdf.]

— A. H. Sobel, E. D. Maloney, D. M. W. Frierson, and I.-S. Kang, 2011b: A systematic relationship between intraseasonal variability and mean state bias in AGCM simulations. J. Climate, 24, 5506-5520.

Knapp, K. R., M. C. Kruk, D. H. Levinson, H. J. Diamond, and C. J. Neumann, 2010: The International Best Track Archive for Climate Stewardship (IBTrACS): Unifying tropical cyclone data. Bull. Amer. Meteor. Soc., 91, 363-376.

Krishnamurti, T. N., R. Correa-Torres, M. Latif, and G. Daughenbaugh, 1998: The impact of current and possibly future sea surface temperature anomalies on the frequency of Atlantic hurricanes. Tellus, 50A, 186-210.

LaRow, T., Y. Lim, D. Shin, E. Chassignet, and S. Cocke, 2008: Atlantic basin seasonal hurricane simulations. J. Climate, 21, 3191-3206.

Lee, M. I., I. S. Kang, and B. E. Mapes, 2003: Impacts of cumulus convection parameterization on aqua-planet AGCM simulations of tropical intraseasonal variability. J. Meteor. Soc. Japan, 81, 963-992.

Liebmann, B., and C. A. Smith, 1996: Description of a complete (interpolated) outgoing longwave radiation dataset. Bull. Amer. Meteor. Soc., 77, 1275-1277.

— H. H. Hendon, and J. D. Glick, 1994: The relationship between tropical cyclones of the western Pacific and Indian Oceans and the Madden-Julian oscillation. J. Meteor. Soc. Japan, 72, 401-411.

Lin, J.-L., and Coauthors, 2006: Tropical intraseasonal variability in 14 IPCC AR4 climate models. Part I: Convective signals. J. Climate, 19, 2665-2690.

—, M.-I. Lee, D. Kim, I.-S. Kang, and D. M. W. Frierson, 2008: The impacts of convective parameterization and moisture triggering on AGCM-simulated convectively coupled equatorial waves. J. Climate, 21, 883-909.

Madden, R. A., and P. R. Julian, 1971: Detection of a 40-50 day oscillation in the zonal wind in the tropical Pacific. J. Atmos. Sci., 28, 702-708.

— and - 1972: Description of global-scale circulation cells in the tropics with a $40-50$ day period. J. Atmos. Sci., 29, $1109-1123$.

Maloney, E. D., and D. L. Hartmann, 2000a: Modulation of eastern North Pacific hurricanes by the Madden-Julian oscillation. J. Climate, 13, 1451-1460.

- and - 2000b: Modulation of hurricane activity in the Gulf of Mexico by the Madden-Julian oscillation. Science, 287, 2002-2004 
, and,- 2001 : The sensitivity of intraseasonal variability in the NCAR CCM3 to changes in convective parameterization. J. Climate, 14, 2015-2034.

Manabe, S., J. L. Holloway Jr, and H. M. Stone, 1970: Tropical circulation in a time-integration of a global model atmosphere. J. Atmos. Sci., 27, 580-613.

Mapes, B. E., and R. B. Neale, 2011: Parameterizing convective organization to escape the entrainment dilemma. J. Adv Model. Earth Syst., 3, M06004, doi:10.1029/2011MS000042.

Rayner, N. A., D. E. Parker, E. B. Horton, C. K. Folland, L. V. Alexander, D. P. Rowell, E. C. Kent, and A. Kaplan, 2003: Global analyses of sea surface temperature, sea ice, and night marine air temperature since the late nineteenth century. J. Geophys. Res., 108, 4407, doi:10.1029/2002JD002670.

Schmidt, G. A., and Coauthors, 2006: Present-day atmospheric simulations using GISS ModelE: Comparison to in situ, satellite, and reanalysis data. J. Climate, 19, 153-192.

Siebesma, A. P., and Coauthors, 2003: A large eddy simulation intercomparison study of shallow cumulus convection. J. Atmos. Sci., 60, 1201-1219.

Slingo, J. M., and Coauthors, 1996: Intraseasonal oscillations in 15 atmospheric general circulation models: Results from an AMIP diagnostic subproject. Climate Dyn., 12, 325-357.

Takayabu, Y. N., T. Iguchi, M. Kachi, A. Shibata, and H. Kanzawa, 1999: Abrupt termination of the 1997-98 El Niño in response to a Madden-Julian oscillation. Nature, 402, 279-282.

Tian, B., D. E. Waliser, E. J. Fetzer, B. H. Lambrigtsen, Y. L. Yung, and B. Wang, 2006: Vertical moist thermodynamic structure and spatial-temporal evolution of the MJO in AIRS observations. J. Atmos. Sci., 63, 2462-2485.

Tokioka, T., K. Yamazaki, A. Kitoh, and T. Ose, 1988: The equatorial 30-60 day oscillation and the Arakawa-Schubert penetrative cumulus parameterization. J. Meteor. Soc. Japan, 66, 883-901.

Tsutsui, J., 2002: Implications of anthropogenic climate change for tropical cyclone activity: A case study with the NCAR CCM2. J. Meteor. Soc. Japan, 80, 45-65.

Vitart, F., J. L. Anderson, and W. F. Stern, 1997: Simulation of interannual variability of tropical storm frequency in an ensemble of GCM integrations. J. Climate, 10, 745-760.
- — - J. Sirutis, and R. E. Tuleya, 2001: Sensitivity of tropical storms simulated by a general circulation model to changes in cumulus parametrization. Quart. J. Roy. Meteor. Soc., 127, 25-51.

Waliser, D., and Coauthors, 2009: MJO simulation diagnostics. J. Climate, 22, 3006-3030.

Wang, W., and M. E. Schlesinger, 1999: The dependence on convection parameterization of the tropical intraseasonal oscillation simulated by the UIUC 11-layer atmospheric GCM. J. Climate, 12, 1423-1457.

Wheeler, M. C., and G. N. Kiladis, 1999: Convectively coupled equatorial waves: Analysis of clouds and temperature in the wavenumber-frequency domain. J. Atmos. Sci., 56, 374399.

— , and H. H. Hendon, 2004: An all-season real-time multivariate MJO index: Development of an index for monitoring and prediction. Mon. Wea. Rev., 132, 1917-1932.

— Intraseasonal Variability in the Atmosphere-Ocean Climate System, W. K.-M. Lau and D. E. Waliser, Eds., Springer, 125173.

Willett, M. R., P. Bechtold, D. L. Williamson, J. C. Petch, S. F. Milton, and S. J. Woolnough, 2008: Modelling suppressed and active convection: Comparisons between three global atmospheric models. Quart. J. Roy. Meteor. Soc., 134, 18811896.

Yasunari, T., 1979: Cloudiness fluctuations associated with the Northern Hemisphere summer monsoon. J. Meteor. Soc. Japan, 57, 227-242.

Yoshimura, J., M. Sugi, and A. Noda, 2006: Influence of greenhouse warming on tropical cyclone frequency. J. Meteor. Soc. Japan, 84, 405-428.

Yu, L., and R. A. Weller, 2007: Objectively analyzed air-sea heat fluxes for the global oceans (1981-2005). Bull. Amer. Meteor. Soc., 88, 527-539.

Zhang, G. J., and M. Mu, 2005: Simulation of the Madden-Julian oscillation in the NCAR CCM3 using a revised ZhangMcFarlane convection parameterization scheme. J. Climate, 18, 4046-4064. 